\title{
Llaqtaqasa: aproximación al consumo de un poblado del Periodo Intermedio Tardío (1100 - 1400 d.C.) en el distrito de Concepción, provincia Vilcas Huamán (Ayacucho)
}

\section{Llaqtaqasa: Approach to the consumption of a Late Intermediate town (1100-1400 A.D) in the district of Concepción, Vilcas Huamán province (Ayacucho)}

\author{
Winnie Celeste Martínez Sulca \\ https://orcid.org/0000-0003-4402-367X \\ Proyecto Qhapaq Ñan, tramo Vilcashuamán-Sangalla \\ wicemar-271193@hotmail.com
}

\section{RESUMEN}

En base al estado de conocimiento de los sitios del Periodo Intermedio Tardío (1100$1400 \mathrm{~d}$. C.) en la provincia de Vilcas Huamán se planteó abordar la problemática de las áreas domésticas y la organización espacial de las mismas a través del estudio del sitio arqueológico Llaqtaqasa ubicado en el distrito de Concepción, provincia Vilcas Huamán (Ayacucho). Para la obtención de datos se realizaron trabajos de prospección sin recojo de material en el sector B que incluyó el levantamiento topográfico y planimétrico de toda el área. Durante la ejecución de la misma se pudo registrar la presencia de un huaqueo al pie de un recinto, la cual fue aprovechada para la extracción de muestras de tierras con el objetivo de obtener algún dato sobre el consumo de los pobladores y ver la relación con el sistema de andenería y corrales presentes en el asentamiento.

Todos los datos obtenidos muestran que los pobladores de Llaqtaqasa tuvieron una economía complementaria basada en la agricultura de altura y la ganadería de camélidos, futuras investigaciones corroborarán lo planteado.

Palabras clave: Llaqtaqasa; consumo; Arqueología; Vilcas Huamán. 


\section{ABSTRACT}

Based on the state of knowledge of the sites of the Late Intermediate Period (1100-1400 A. P.) in the province of Vilcas Huamán, it was proposed to address the problem of domestic areas and their spatial organization through the study of the archaeological site Llaqtaqasa located in the Concepción district, Vilcas Huamán province (Ayacucho). To obtain data, prospecting works were carried out without collecting material in sector $\mathrm{B}$, which included the topographic and planimetric survey of the entire area. During the execution of the same, the presence of a burrow at the foot of an enclosure could be registered, which was used to extract samples of land in order to obtain some data on the consumption of the inhabitants and see the relationship with the Andenería system and pens present in the settlement.

All the data obtained shows that the residents of Llaqtaqasa had a complementary economy based on high-altitude agriculture and camelid farming, future research will corroborate what has been stated.

Keywords: Llaqtaqasa; consumption; Archaeology; Vilcas Huamán.

ReCibido: 18/02/2020 - AcePTADO: 01/07/2020 - PublicAdo: 10/05/2021

\section{UBICACIÓN}

El sitio arqueológico Llaqtaqasa está ubicado entre los anexos de Astanya y Pirhuabamba, pertenecientes al distrito de Concepción, provincia Vilcas Huamán, departamento Ayacucho (ver figura 01). Entre las coordenadas UTM: N 8497552 / E 621655 emplazada entre los 4000 a 4100 m s. n. m.

Se encuentra en la margen izquierda del río Pampas (cuenca media), a $10.7 \mathrm{~km}$ al noreste de la ciudad de Vilcas Huamán, $1.2 \mathrm{~km}$ al sur del centro poblado de Astanya, $2.2 \mathrm{~km}$ al este del centro poblado de Pirhuabamba y $7 \mathrm{~km}$ al oeste del río Pampas.

Se emplaza en la cima y ladera de un promontorio rocoso conocido por los pobladores como Llaqtaqasa (denominada pampa Auquillama en la carta nacional Chincheros 28 O). Este promontorio se encuentra conformado por dos colinas orientadas de sureste a noroeste; el relieve de este sitio es abrupto y se encuentra delimitado por las quebradas de Antapite Cruz (lado oeste) y Manzanayocc (lado este), estas quebradas recorren las zonas altas, pasan por el valle y culminan en el río Pampas.

El relieve de esta área forma parte del grupo de rocas Pucará constituido por calizas gris azulinas en bancos medios a gruesos con nódulos de chert (Sílex Pedernal) formado en el periodo Triásico Superior (228.0 \pm 2 hasta 199.6 $\pm 0,6$ millones de años) de la era Mesozoica (Carta Geológica INGEMMET Chincheros “28 O"). 


\section{ENTORNO GEOGRÁFICO}

Llaqtaqasa se ubica entre los 4000 a $4100 \mathrm{~m} \mathrm{s.} \mathrm{n.} \mathrm{m} \mathrm{en} \mathrm{promedio} \mathrm{(ver} \mathrm{figura} \mathrm{02),}$ por lo que, según Pulgar Vidal (1996), se ubicaría en el límite entre la región Suni y Puna. Sin embargo, Llaqtaqasa presenta características climatológicas propias de la región Suni.

En esta área el aire es frío y seco, actualmente en esta zona no hay una población estable debido a la altura y el frío, por lo tanto, estas áreas son utilizadas como lugares de pastoreo. Dentro de esta se distinguen pastos naturales, hierbas aromáticas y medicinales, además de la mayor parte de los cultivos en secano, entre ellos papa, olluco, mashua, quinua, cebada y avena forrajera; también existen ichu, taya taya, chillwer, chillca, Kallwayzu, qinwua, etc.

El clima corresponde al templado frío, se producen heladas y bruscos descensos de temperatura en las noches despejadas que afectan los cultivos. La temperatura media anual fluctúa entre los $7-10^{\circ} \mathrm{C}$.

Respecto a la fauna, están las vizcachas, aves como el halcón, perdiz y aves de laguna. En cuanto a la flora tenemos al ichu, waraqu kichka, taya, chachas, Qanlla, Qapchiko, Kallwayzu, entre otros, sobresaliendo este último.

El sitio arqueológico se ubica en la cima de un afloramiento rocoso con un relieve accidentado, sin embargo en los alrededores (300 a $500 \mathrm{~m}$ ) se observan grandes pampas (ver figuras 03 y 04) ubicadas sobre los $3500 \mathrm{~m} \mathrm{~s}$. n. m., donde crecen gran cantidad de ichu, Kallwayzu, puya de raimondi, entre otros. Además, en esta área se ha podido identificar varios ojos de agua debido a ello esta zona es utilizada como pastoreo por la población local.

\section{Recursos hídricos}

Alrededor del sitio arqueológico Llaqtaqasa se han podido identificar una serie de ojos de agua, la gran mayoría se ubica en la parte baja; sin embargo, el ojo de agua más grande se encuentra al pie del cerro Llaqtaqasa, en la zona conocida como Llaqtaqasa Cucho. Estos ojos se ubican entre 200 a $1000 \mathrm{~m}$ de distancia y tienen un promedio de $5 \mathrm{~m}$ de diámetro.

\section{El río Pampas}

El sitio arqueológico Llaqtaqasa se ubica a unos $7 \mathrm{~km}$ aproximadamente al este del río Pampas (ver figura 05), perteneciente a la cuenca media. El Pampas es el límite natural de la provincia de Vilcas Huamán respecto a las provincias de Víctor Fajardo y Sucre (Ayacucho) por el sur; Andahuaylas y Chincheros (Apurímac) por el este.

Geográficamente la cuenca del río Pampas se encuentra ubicada en la sierra central sur del Perú, en la vertiente del Atlántico, políticamente comprende las provin- 


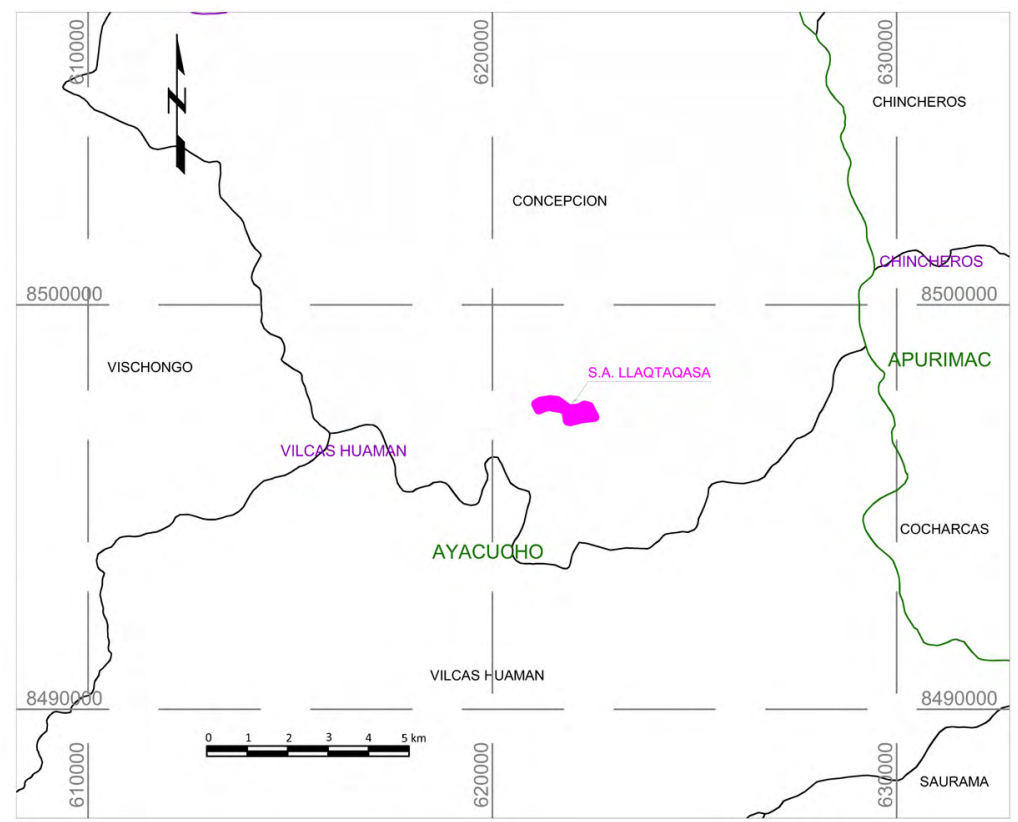

Figura 01. Vista de ubicación política del sitio arqueológico Llaqtaqasa.

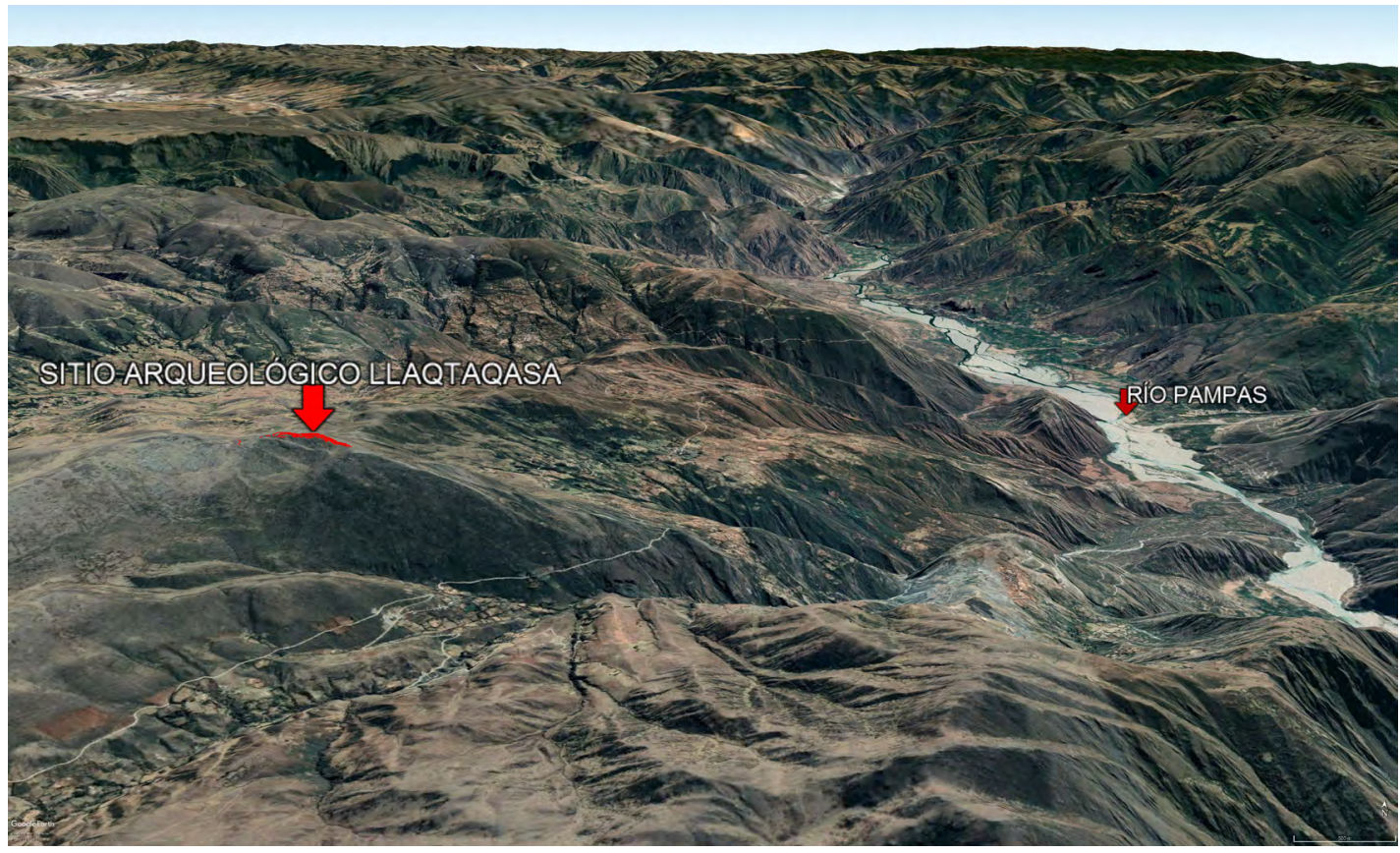

Figura 02. Vista de ubicación del sitio arqueológico Llaqtaqasa en relación al río Pampas (fuente: Google Earth). 


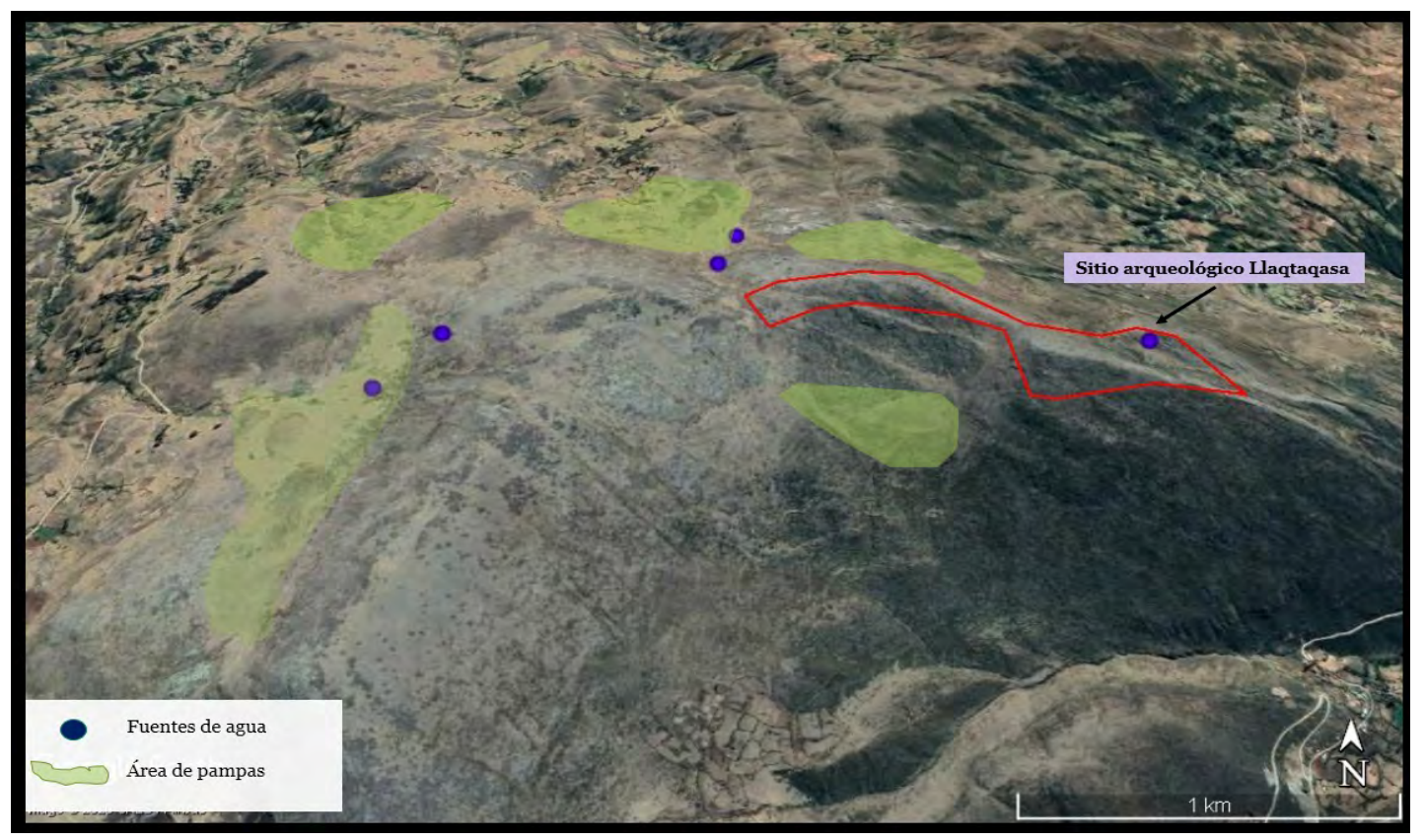

Figura 03. Vista fuentes de agua y área de pampas asociados al sitio arqueológico Llaqtaqasa (Google Earth 2020).

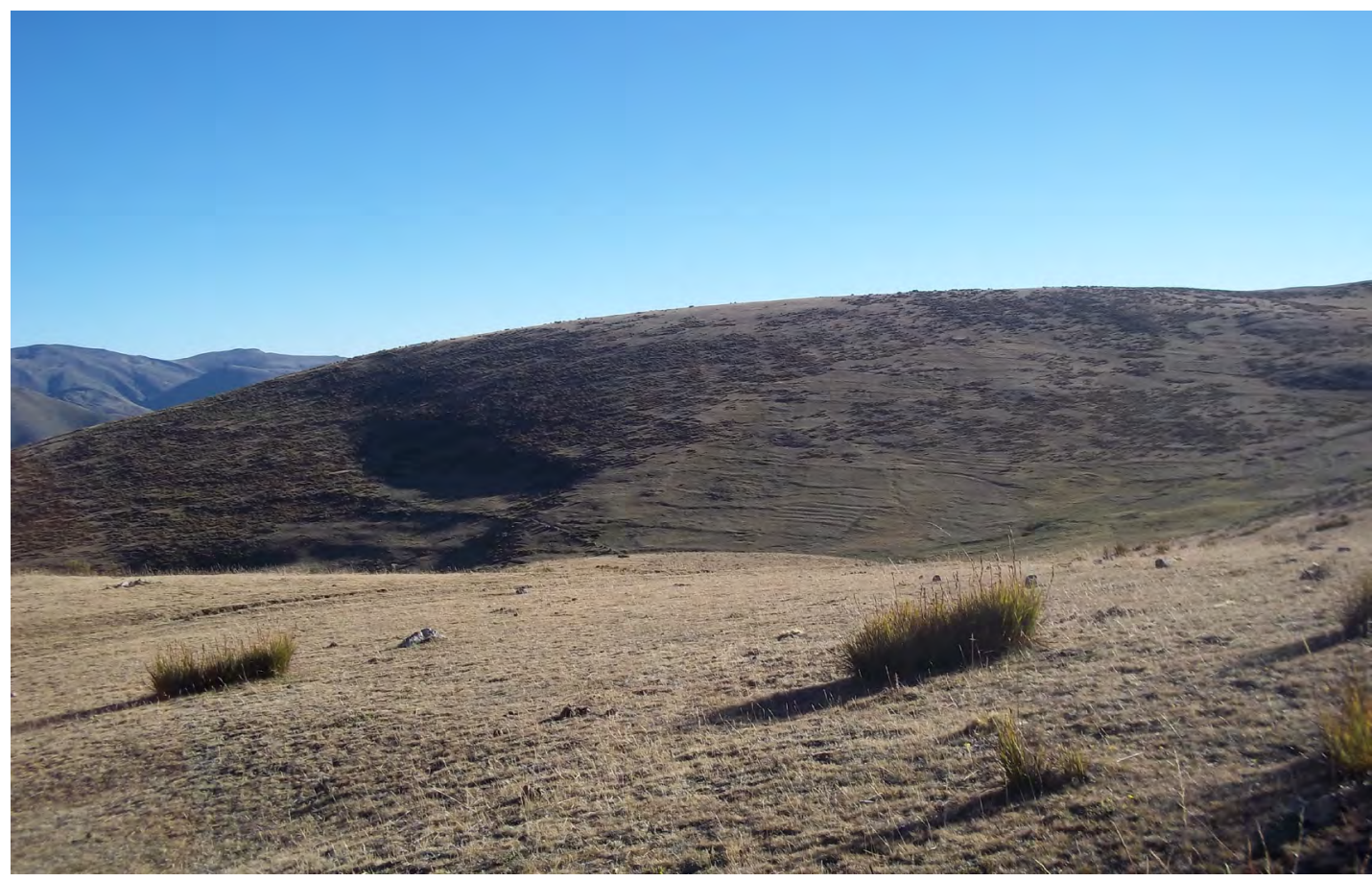

Figura 04. Vista de áreas de pampas asociadas al sitio arqueológico Llaqtaqasa. 


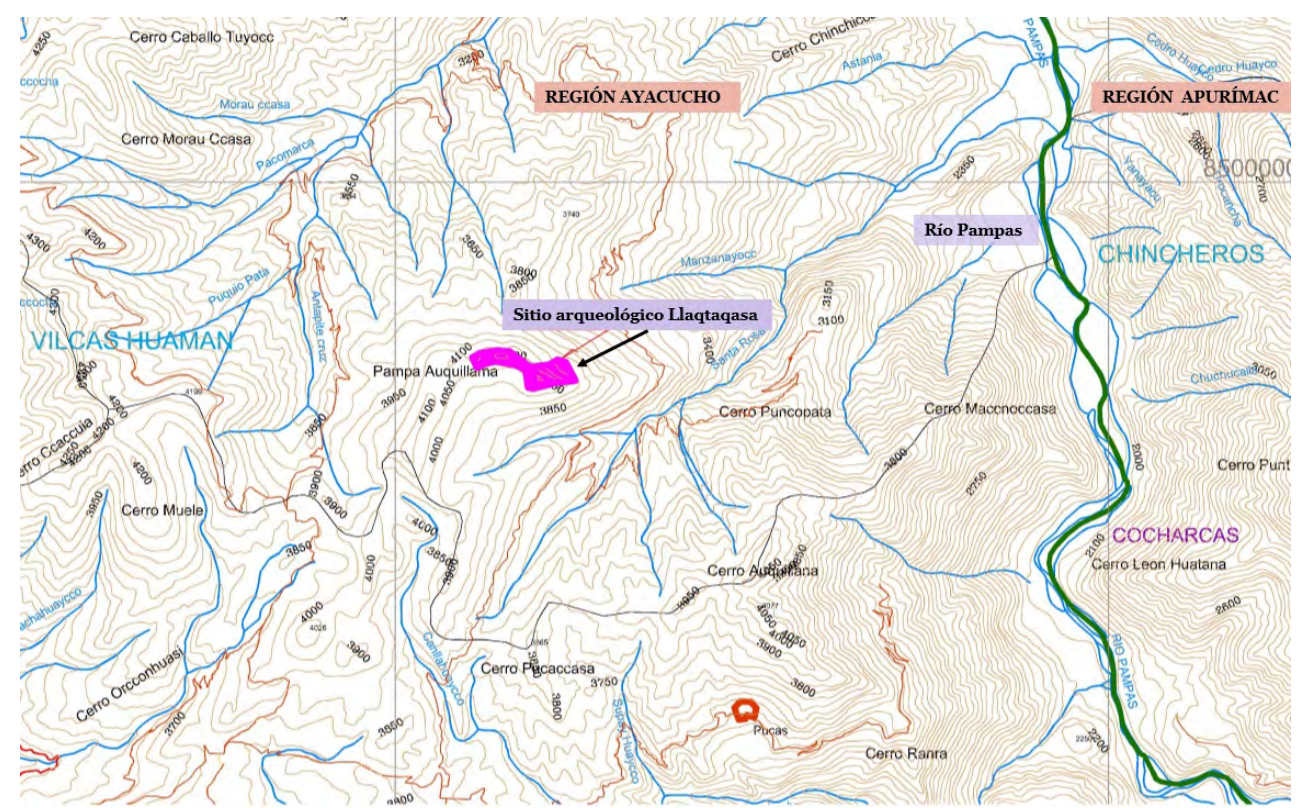

Figura 05.Vista de ubicación del sitio arqueológico Llaqtaqasa en relación al río Pampas (líneas verdes).

cias de Huamanga, Cangallo, Fajardo, Huancasancos, Lucanas, Sucre, Vilcas Huamán, La Mar de la región Ayacucho; las provincias de Chincheros y Andahuaylas (región Apurímac) y la provincia de Castrovirreyna (región Huancavelica). El río Pampas presenta una superficie de drenaje de $23236,37 \mathrm{~km}^{2}$, desde su naciente, en la Laguna Choclococha, a una altitud aproximada de $4454 \mathrm{~m} \mathrm{s.} \mathrm{n.} \mathrm{m.,} \mathrm{hasta} \mathrm{su} \mathrm{desembocadura}$ en la margen izquierda del río Apurímac, a una altitud aproximada de $975 \mathrm{~m} \mathrm{s.} \mathrm{n.} \mathrm{m.}$ La cuenca del río Pampas se encuentra ubicada entre las coordenadas UTM: Datum: WGS 84: 473000 y 710000 E y 8590000 y $8365000 \mathrm{~N}$.

La Cuenca Media comprende las provincias de Vilcas Huamán, Sucre, Huamanga y Apurímac (Chincheros y Andahuaylas).

La cuenca del río Pampas es el ecosistema hídrico más importante con que cuenta el distrito incluso la provincia de Vilcas Huamán y una de las más grandes de la región de Ayacucho.

Su importancia radica desde tiempos prehispánicos; por ejemplo, durante el Periodo Intermedio Tardío sirvió como límite natural de diferentes grupos étnicos que vivieron tanto en la margen derecha e izquierda, posteriormente durante el Horizonte Tardío fue llamado Willkamayu y probablemente fue aprovechado conjuntamente con el valle en el distrito de Concepción, ya que se registró evidencias de un posible camino inca que uniría esta parte del valle con la ciudadela inca de Vilcashuamán: 
Las chacras de Astania lindan por la parte de arriba con tierras Parra de Cochachi que poseen los indios del pueblo de Concepción, por abajo con tierras del propio convento de nuestra señora de la Merced y las otras tierras la divide una acequia de agua que pasa por el medio de ellas y va a dar al lindero hasta las tierras que posee Francisco Rodas llamada Tugahuapar (no legible) dicha acequia va a dar a un puente de piedra y para el camino real que va al pueblo de Vilcas y por un lado a un corralón llamado Mataruyocc y por el otro que va corriendo hasta la barranca llamada Llipiacaca. (AGN, 1715, legajo 24, cuaderno 449).

Durante el Periodo Colonial, en esta parte del valle se instalaron una serie de haciendas, obrajes y reducciones tales como la hacienda de Astania, hacienda de Pacomarca, hacienda Mejorada, hacienda Occenay, hacienda Santa Rita, reducción de Concepción; hacia el norte (pasado el pueblo de Concepción) tenemos el obraje de Ccaccamarca, la hacienda de Ninabamba, entre otros. Esta zona fue aprovechada al máximo y tuvo condiciones óptimas para la instalación de este tipo de infraestructuras, a comparación con otras partes del río que forman valles encajonados. En la actualidad, el río Pampas alberga una diversidad de peces nativos como el bagre, trucha, entre otros. Dentro de la vegetación tenemos: warangu, mulli, cabuya, pati, palta, papaya, naranja, guinda.

\section{ANTECEDENTES ARQUEOLÓGICOS, ETNOHISTÓRICOS E HISTÓRICOS}

\section{Antecedentes arqueológicos}

Si realizamos un resumen de los estudios arqueológicos realizados en la provincia en torno a los sitios del Periodo Intermedio Tardío partimos señalando a Lumbreras (1959), quién entre los años 1956 a 1958 inició sus exploraciones en la sierra central, trató de definir la existencia de los grupos denominados chancas (mencionados en las crónicas) para el área de Ayacucho. En el distrito de Vilcas Huamán registró una serie de sitios como Pillucho, Lawirasqa, entre otros; estos estarían conformados por estructuras circulares asociados a cerámica del estilo Arqalla; por lo tanto, estos sitios serían del Periodo Intermedio Tardío y estarían asociados a los grupos denominados chankas, quiénes "son contemporáneos e inmediatamente anterior a los Incas” (Lumbreras, 1959, p. 237).

Carlos Guzmán (1959) en 1958 realizó trabajos de investigación en Vilcas Huamán registrando sitios arqueológicos de diferentes periodos que van desde el Pre cerámico hasta el Horizonte Tardío. Los sitios del Periodo Intermedio Tardío se encontraron asociados a cerámica del estilo Arqalla. Uno de los aportes importantes de Guzmán es que propone el primer cuadro cronológico para Vilcas Huamán señalando a la cerámica Arqalla como perteneciente al Periodo Intermedio Tardío. 
Chahud (1966) en 1965 realizó trabajos de excavación y prospección en Vilcas Huamám, resultado de las excavaciones posicionó estratigráficamente la cerámica del estilo Arqalla como posterior a Wari y previo a la ocupación inca. Incluso encontró cerámica del estilo Arqalla asociada a cerámica inca, lo cual lo llevó a plantear su contemporaneidad.

Ochante (2001) entre los años 1990 y 2000 realizó trabajos de prospección en el distrito de Concepción (Vilcas Huamán), producto de ello registró una serie de sitios perteneciente tanto al Periodo Intermedio Tardío y Horizonte Tardío. Este investigador es el único referente en torno al sitio arqueológico Llaqtaqasa, lo describe de manera general clasificándolo como un sitio de habitación conformado por un sistema de estructuras circulares asociados a corrales distribuidos en la cima de un cerro y protegido por murallas pertenecientes al Periodo Intermedio Tardío, esto en base a la cerámica hallada en superficie. Además de Llaqtaqasa, registró los sitios de Huanacauri, Maucallaqta, Churcurumi, Urquncorral, Pucara, Llaqtapata, Qullqui Pedro, Tuirunga y Muela Qasa, estos estarían conformados por estructuras circulares hechas a base de piedras unidas y distribuidas de "manera desordenada" a lo largo de la cima de los cerros, contarían con un sistema de murallas, corrales y zanjas, también registró sitios de inhumación y andenes.

A partir del 2003 se realizaron una serie de trabajos de prospección y reconocimiento de áreas dentro de la provincia de Vilcas Huamán por parte de estudiantes de la Universidad Nacional de Huamanga con el objetivo de proponer secuencias cronológicas relativas y caracterizar los asentamientos de los distintos periodos.

Vaquerizo (2003), realizó un reconocimiento en San Antonio de Cocha (distrito de Huambalpa), Castro (2007) en la cuenca del río Itanayuq (Pujas), Quijano (2010) entre las quebradas de Saurama y Urpay Puquio (distrito de Carhuanca), Mendoza (2010) en la margen izquierda de los ríos Yanamayu y Pampas pertenecientes al distrito de Vilcas Huamán, Quispe y Rojas (2010) en la margen izquierda del río Qatunmayo (distrito Vischongo), Cisneros (2011) en la margen izquierda del río Pampas (distrito Huambalpa) y Mendoza (2014) al sureste del distrito de Vilcas Huamán.

Todos ellos han registrado sitios desde el Periodo Formativo hasta el Horizonte Tardío, concluyendo que los sitios del Periodo Horizonte Medio están ubicados en las partes bajas, cerca de los valles, asociados a cerámica del estilo Huamanga y a un sistema de andenerías. Respecto a los sitios del Periodo Intermedio Tardío, estarían ubicados en las partes altas (cima de los cerros) asentados, en su gran mayoría, sobre áreas sin ocupaciones previas, algunos estarían asociados a murallas, zanjas, abrigos rocosos, andenes y corrales. Se encontrarían compuestos por una serie de recintos circulares de piedras entre 4 a $6 \mathrm{~m}$ de diámetro orientados sin un orden aparente. Para el caso de Pujas, Castro (2007) estableció dos categorías de sitios del 
Intermedio Tardío para el área: Pukarás o fortalezas y poblados sin fortificación. El primer tipo estaría caracterizado por su inaccesibilidad, presencia de un sistema defensivo y control de acceso, estos se encuentran compuestos por una serie de recintos circulares entre 4 a $6 \mathrm{~m}$ de diámetros aglutinados entre 4 a 5 alrededor de un espacio (patio) y distribuidos a lo largo de la cima de los cerros, además estarían asociados a corrales, abrigos rocosos (donde se encontraron restos humanos), terrazas agrícolas, murallas defensivas, zanjas, estructuras rectangulares, estructuras circulares pequeñas, entre otros. Por otra parte, los poblados sin fortificación son aquellos que carecen de un sistema de defensa, tienen fácil acceso y se encuentran asociados a terrazas agrícolas (Castro, 2007).

\section{Antecedentes etnohistóricos e históricos}

Para la zona de Vilcas Huamán se mencionan la presencia de dos grupos étnicos durante el Periodo Intermedio Tardío: Tanquiguas y Vilcas (Willca), estos se encuentran documentados al interior de crónicas (Guamán Poma, 1980 [1615]), (Garcilaso, 1976 [1906]) y documentos históricos (Carabajal, 1965 [1881]), y Cook, 1975).

Guamán Poma (1980) señala a los Tanquiguas y Vilcashuamán (Willcas) como dos grupos distintos que fueron conquistados por el inca Viracocha.

"Demás de la conquista de su padre conquistó los Soras, Andamarcas, Lucanas, Angaraes, Tanquiua, Vilcasguaman hasta Tayacaja, Guamanjauja, Hanan, Luriguanca, Yauyos y algunos yunguas" (Guamán Poma, 1980, p. 79)

Por su parte Garcilaso (1976) [1609], señaló que Vilcas Huamán estuvo conformada por la nación de los Villcas y Hancohuallu, que pertenecerían a los chancas:

"De allí pasó el Inca a la provincia y nación llamada Hancohuallu y Uillca, que los españoles llaman Vilcas, y con la misma pesadumbre se sujetaron a su imperio, porque estas naciones, que también son Chancas, eran señores de otras provincias que habian sujetado con las armas, y de día en día iban ganando con mucha ambición y trataban los nuevamente ganados con soberbia y tiranía; la cual reprimió el Rey Inca Roca con sujetarlos a su obediencia, de que todos ellos quedaron muy lastimados y guardaron el rencor en sus ánimos" (Garcilaso de la Vega, 1976, p. 197).

Carabajal (1965 [1881] en el año 1586 realizó la visita a la provincia de Vilcas Huamán como corregidor de la misma, este texto fue publicado en "Relaciones Geográficas de Indias-Perú". En esta detalla la forma de vivir, vestimenta, recursos de cada curato perteneciente a la provincia, señala además que todos los pobladores naturales de Vilcashuamán fueron transpuestos por los incas una vez conquistado esta tierra, los únicos originarios serían los Tanquiguas quienes vivieron en Huambalpa, Cocha, Guaras (Guarcas), Guamanmarca (parte sur de lo actualmente es Vilcas Huamán) y fueron encomendados, durante la Colonia, a Hernán Guillén. 
Cook (1975), señala en base a la visita de Toledo, que en Vilcashuamán se encontraba el repartimiento de los Tanquiguas encomendada a Hernán Guillén de Mendoza con unos 745 indios tributarios, quienes no sólo pagaban en monedas sino también a través de productos como el maíz, papa, trigo, entre otros.

\section{EL SITIO ARQUEOLÓGICO LLAQTAQASA}

El asentamiento arqueológico Llaqtaqasa tiene una orientación de sureste a noroeste, cuenta con un área total aproximado de 29.27 hectáreas. Este fue dividido en tres sectores denominados: "sector A", "Sector B" y "Sector C" (ver figura 06), la presente responde a criterios técnicos clásicos y a la diferenciación del espacio construido a través de la ubicación, emplazamiento y presencia de una serie de componentes arquitectónicos.

Nuestro objetivo de investigación fue determinar la función del sector B, identificar y describir las características que presentan las estructuras arquitectónicas que lo componen y, por último, describir la organización interna, para ello se realizó el levantamiento topográfico y planimétrico de todas las estructuras arquitectónicas. Posteriormente, se realizaron una serie de prospecciones sistemáticas con una cobertura total en base a transectos lineales con el objetivo de identificar, describir todos los componentes arquitectónicos y recolectar información de los objetos muebles, este no contempló recolección ni traslado de material; por lo tanto, todo el registro gráfico y escrito se realizó in situ, todo el material fue ubicado espacialmente y fue plasmado en el plano arquitectónico del sector.

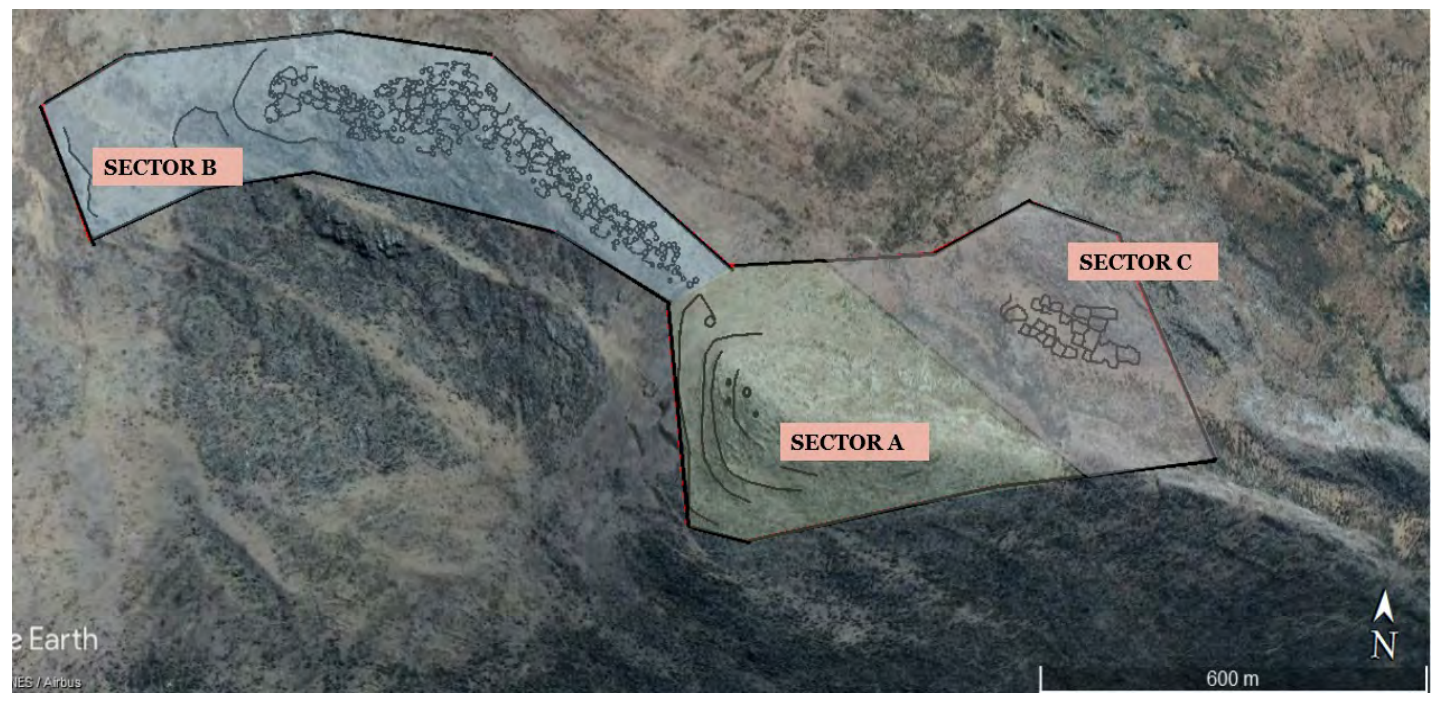

Figura 06.Vista de sectores del sitio arqueológico Llaqtaqasa (fuente: Google Earth). 
El sector A, se encuentra ubicado en la cima y ladera de la segunda colina del cerro Llaqtaqasa, específicamente al lado sureste del asentamiento, colinda por el noroeste con el "sector B", separado de este último por medio de una serie de muros doble cara (muros compuestos), esta colina es la más alta ya que tiene una altitud de $4200 \mathrm{~m}$ s. n. m., aproximadamente. El sitio se encuentra conformado por una serie de muros de contención doble cara (muros compuesto) en forma de "U" que bordean la parte inferior de dicha colina, sobre las últimas se registraron una serie de recintos de planta circular agrupadas alrededor de un espacio común "Grupo-Patio" (Earle, 1987) y otras organizadas independientemente.

El "sector C" (ver figura 07) se encuentra ubicado al pie del cerro Llaqtaqasa, en la zona conocida por los pobladores como "Llaqtaqasa Cucho", se encuentra al noreste del asentamiento y se emplaza en una zona relativamente plana. La superficie se encuentra conformada por una serie de afloramientos rocosos pertenecientes al grupo de rocas Pucará constituido por calizas gris azulinas, en algunas secciones se registraron una serie de fallas geológicas. El sector se encuentra conformado por una serie de estructuras arquitectónicas de planta variada de gran tamaño organizadas en forma celular, estas corresponderían a corrales, algunas se encuentran asociadas a recintos circulares.

Alrededor del sitio arqueológico Llaqtaqasa, a una distancia entre $0.4-1.2 \mathrm{~km}$, se registró una serie de corrales de gran tamaño (ver figura 08), todas ellas ubicadas en zonas relativamente planas por debajo de los $4000 \mathrm{~m} \mathrm{~s}$. n. m., asociadas a ojos de agua y afloramientos rocosos. En general, estos corrales se organizan espacialmente de forma celular y su forma es variable desde semicircular, ovalada y cuadrangular. Se ubican a una distancia no menor de $100 \mathrm{~m}$ respecto a ojos de agua y afloramientos rocosos.

A $500 \mathrm{~m}$ al este del sitio arqueológico Llaqtaqasa, se registró un sistema de andenerías orientados de norte a sur (ver figuras 09 y 10), estos se ubican sobre los $3960 \mathrm{~m} \mathrm{~s}$. n. m. Se emplaza a lo largo de una pequeña quebrada en una superficie descendiente de sur a norte. La extensión es de $100 \mathrm{~m}$ de largo de norte a sur y $90 \mathrm{~m}$ de ancho de este a oeste, haciendo aproximadamente un total de 0.9 ha. Asociado a este se registró una serie de recintos de planta circular elaborados a base de piedra.

El "sector B" (ver figura 11) se encuentra ubicado en la cima del cerro Llaqtaqasa, al noroeste del asentamiento, presenta una orientación de este a oeste, ocupa una superficie de 12.48 ha (785 m de este a oeste y $159 \mathrm{~m}$ de norte a sur), se emplaza en una superficie relativamente ondulada donde predominan afloramientos rocosos, se ubica sobre una altura que varía entre 4091 a $4116 \mathrm{~m} \mathrm{s.} \mathrm{n.} \mathrm{m.}$

El sector se encuentra conformado por una serie de recintos circulares y ovalados (ver figura 12), estos se organizan alrededor de un espacio común "patio" de- 


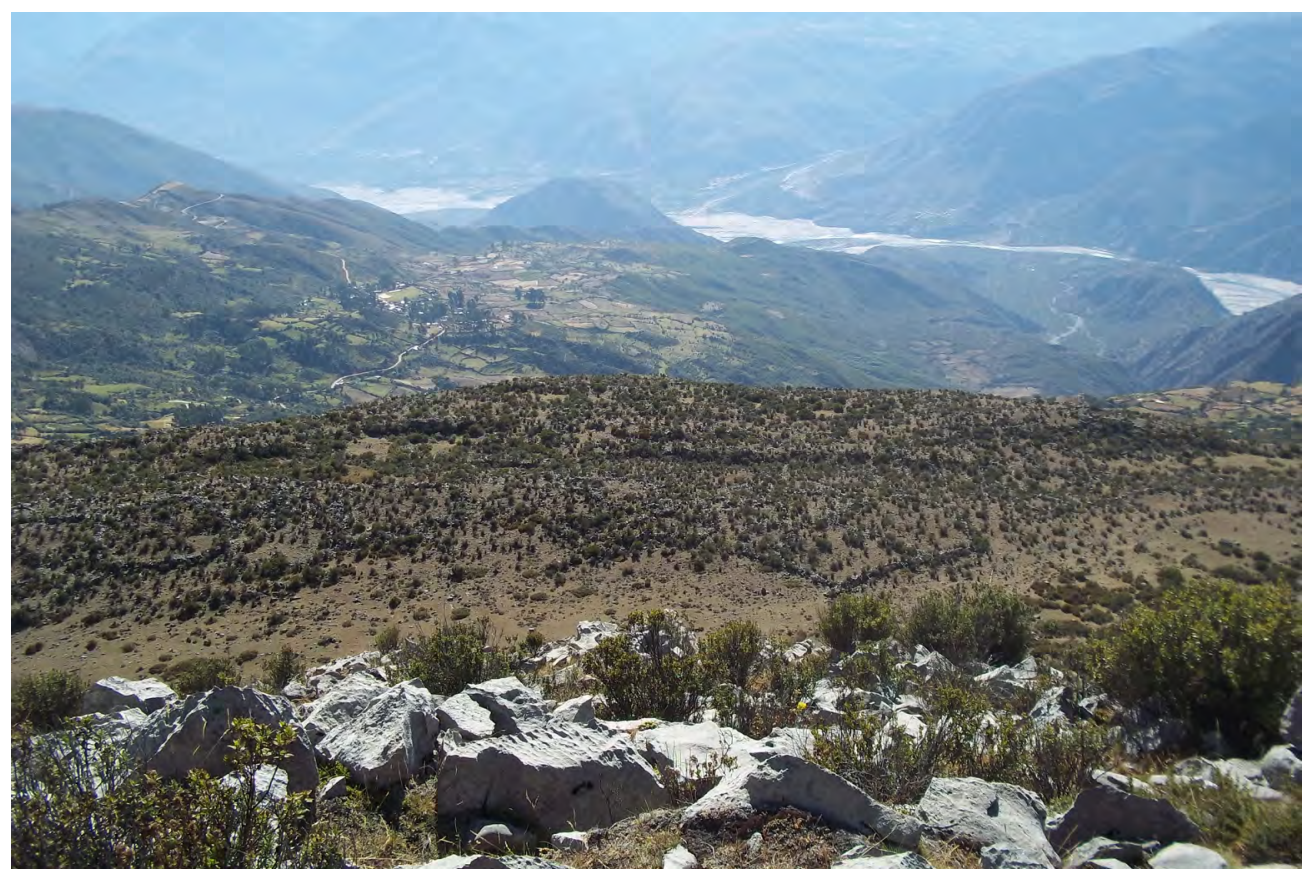

Figura 07. Vista general del sector $C$, nótese la presencia de corrales.

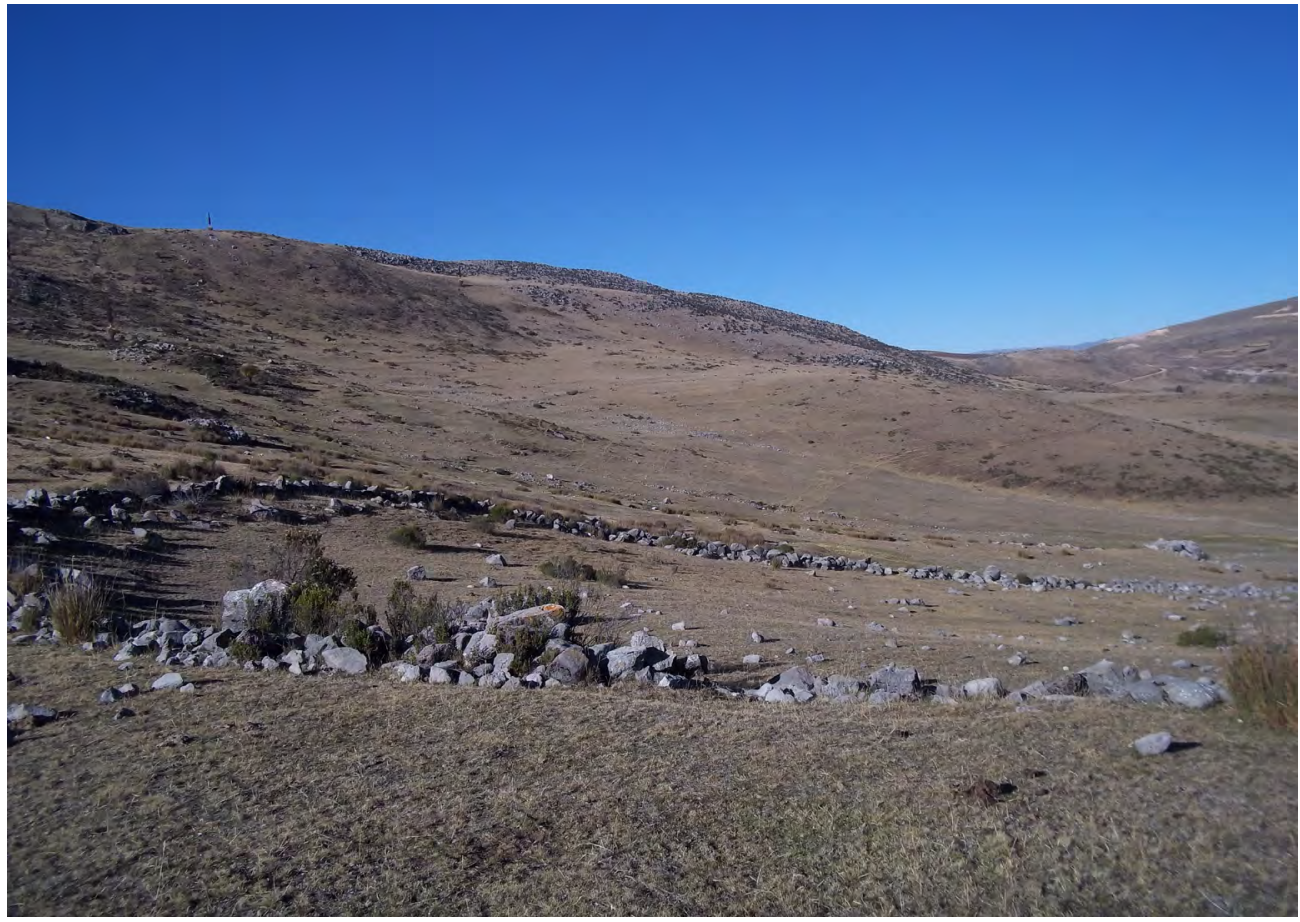

Figura 08. Vista general de corrales asociados al sitio arqueológico Llaqtaqasa. 
Winnie C. Martínez Sulca / Llaqtaqasa: aproximación al consumo de un poblado del Periodo Intermedio...

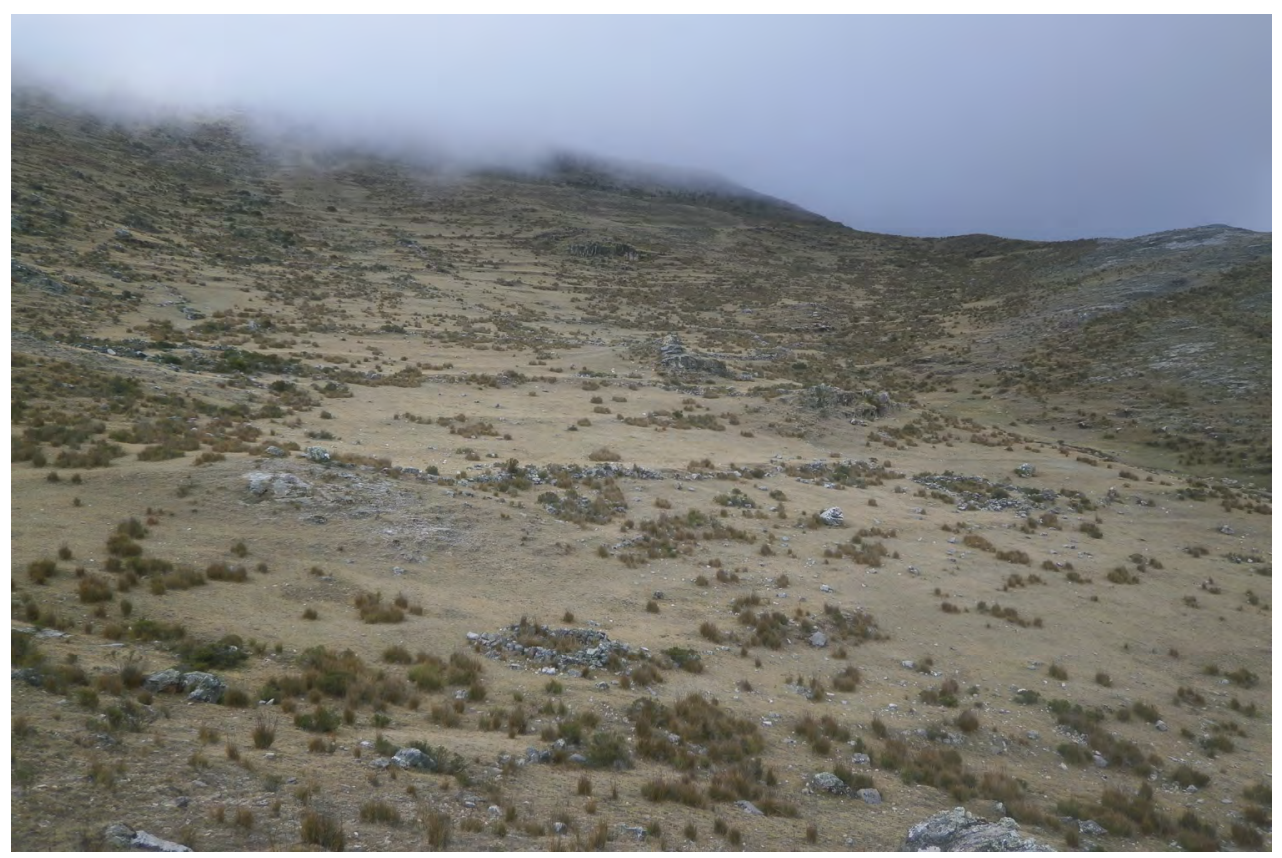

Figura 09. Vista general de sistema de andenería asociados al sitio arqueológico Llaqtaqasa.

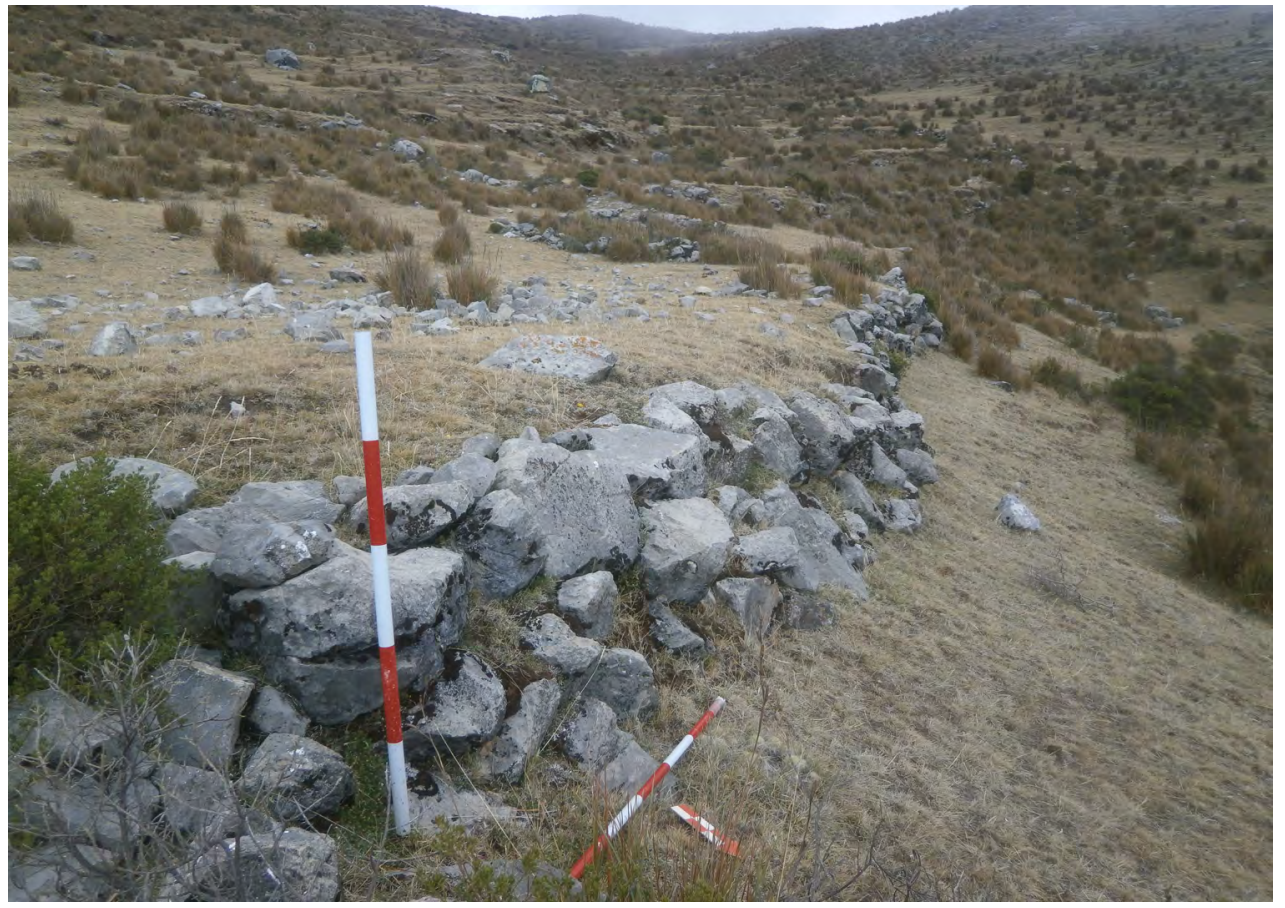

Figura 10.Vista lateral de sistema de andenerías en las proximidades de Llaqtaqasa. 


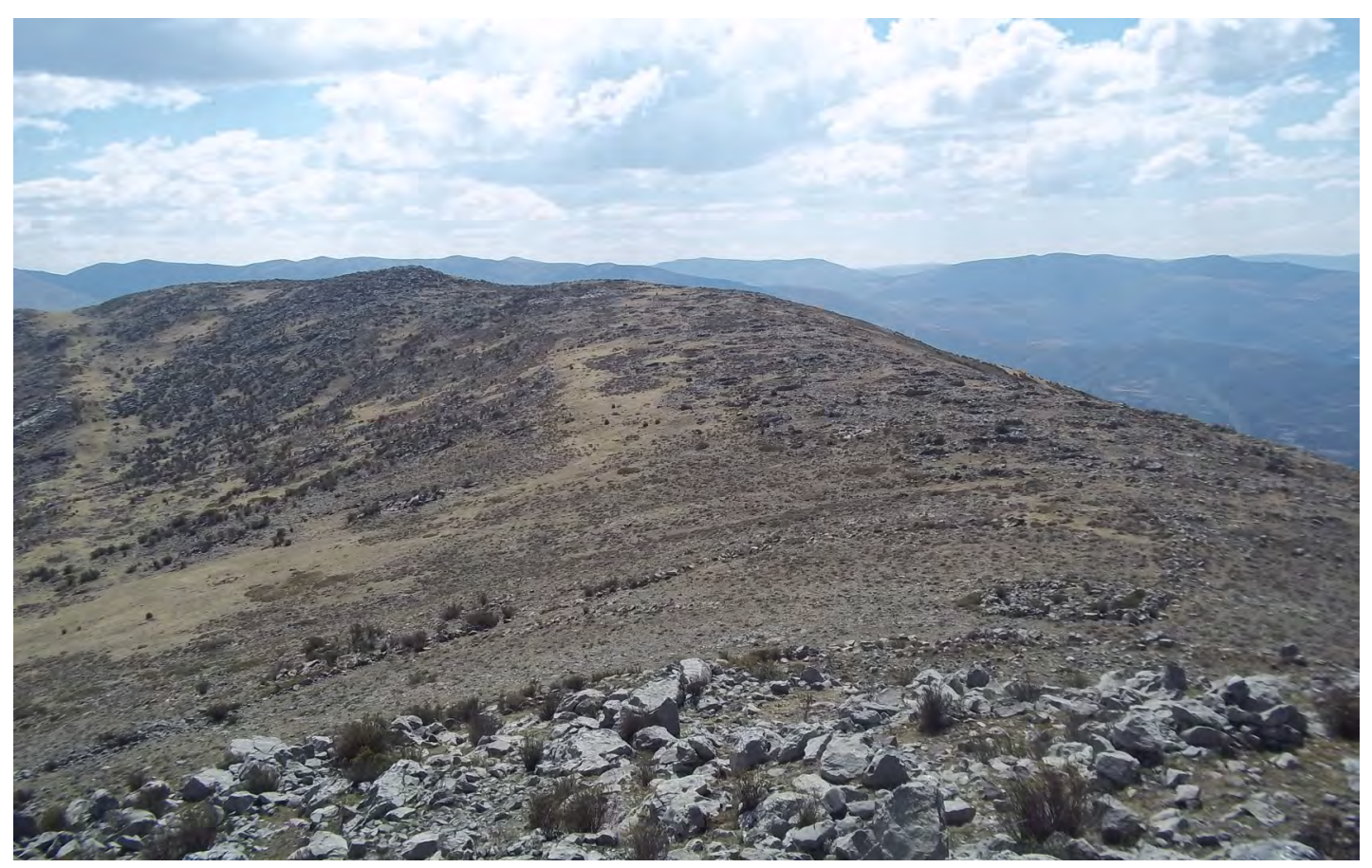

Figura 11.Vista este-oeste del sector B del sitio arqueológico Llaqtaqasa.

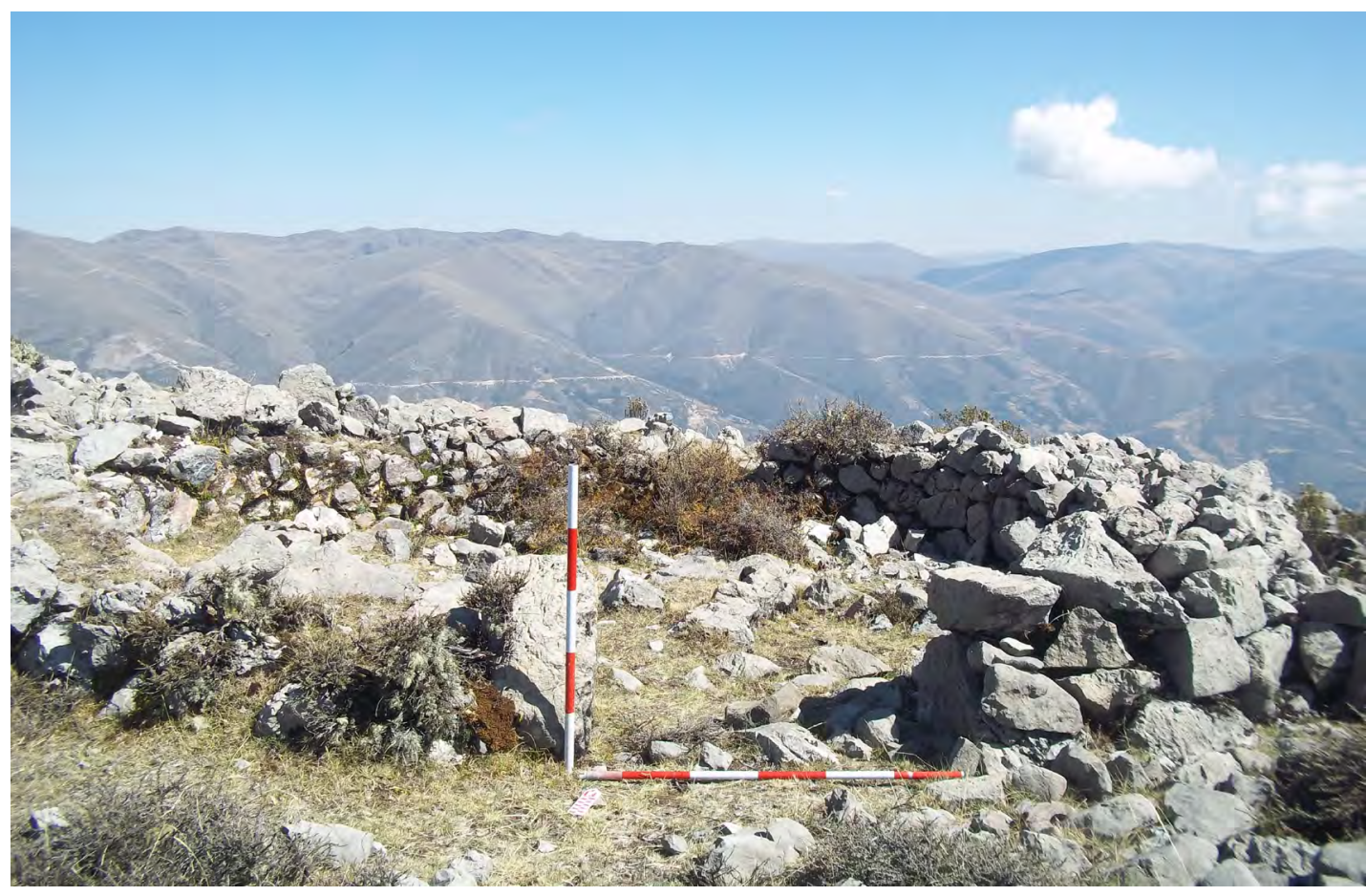

Figura 12.Vista general de un recinto perteneciente al sector B del sitio arqueológico Llaqtaqasa 
limitados a través de muros doble cara, este sistema de organización se denomina "Grupo-Patio" (definido para el Alto Mantaro por T-Earle (1987). Cada Grupo-Patio se encuentra conformado entre 1 a 6 recintos circulares agrupados y orientados en relación a un patio, este último se encuentra delimitado y separado de otro "Grupo-Patio" por medio de muros doble cara de regular altura. Los vanos de acceso de los recintos se orientan al interior del patio.

Sobre la zona medianamente accesible donde no hay obstáculos naturales, exactamente en el extremo oeste del sector B, se registraron una serie de muros perimetrales doble cara, estas delimitan toda la parte oeste del sector limitando el acceso hacia el mismo. En total, se registraron 3 muros perimetrales de diferentes dimensiones orientadas de norte a sur separadas entre 20 a $100 \mathrm{~m}$. La superficie del espacio entre los muros se encuentra conformada por afloramientos rocosos y tiene una pendiente descendente de este a oeste, en el interior no se registró ningún tipo de estructura arquitectónica.

En superficie se halló fragmentos de cerámica doméstica correspondiente a cántaros, ollas, platos, vasos, jarras, muchos de estos guardan relación con los tipos de cerámica planteado para la región como el grupo Arqalla y Tanta Orqo (Gonzáles et al,1987) y los tipos de cerámica definidos por Mendoza (2010) en el sitio arqueológico Campanayuq Rumi (grupo campanayuq marrón rojizo alisado simple) todos del Periodo Intermedio Tardío, no se registró cerámica del estilo inca. Respecto al material lítico se registró rompeterrones, batanes, manos de moler, mortero y machacador.

\section{RESULTADOS}

Durante los trabajos de campo se pudo visualizar al pie del paramento externo del recinto $\mathrm{N}^{\circ} 130$, perteneciente al sector $\mathrm{B}$ un huaqueo de $70 \mathrm{~cm}$ de largo y $50 \mathrm{~cm}$ de ancho (ver figura 13), esto nos permitió identificar las unidades estratigráficas presentes y a la vez realizar un dibujo de corte (ver figuras 14 y 15).

Dentro de las UEs identificadas tenemos:

UE 01: La UE 01 se encuentra compuesta por tierra orgánica color negro de consistencia semisuelta, piedras poliédricas pequeñas y raíces, presenta una textura fina, la superficie es irregular, al interior se registró fragmentos de cerámica de pasta naranja, presenta un grosor de $18 \mathrm{~cm}$. La UE 01 se adosa al paramento externo del recinto $\mathrm{N}^{\circ} 130$, se ubica sobre la UE 02 .

UE 02: La UE 02 se encuentra compuesta por tierra de color negro de consistencia semicompacta, piedras angulosas pequeñas, es de textura fina, la superficie es irregular, al interior se registró fragmentos de cerámica de pasta marrón, restos óseos de animal (algunos se encontraban carbonizados) y carbón. Presenta un grosor de $18 \mathrm{~cm}$, se ubica debajo del muro del recinto $\mathrm{N}^{\circ} 130$ y de la UE 01, sobre la UE 03. 


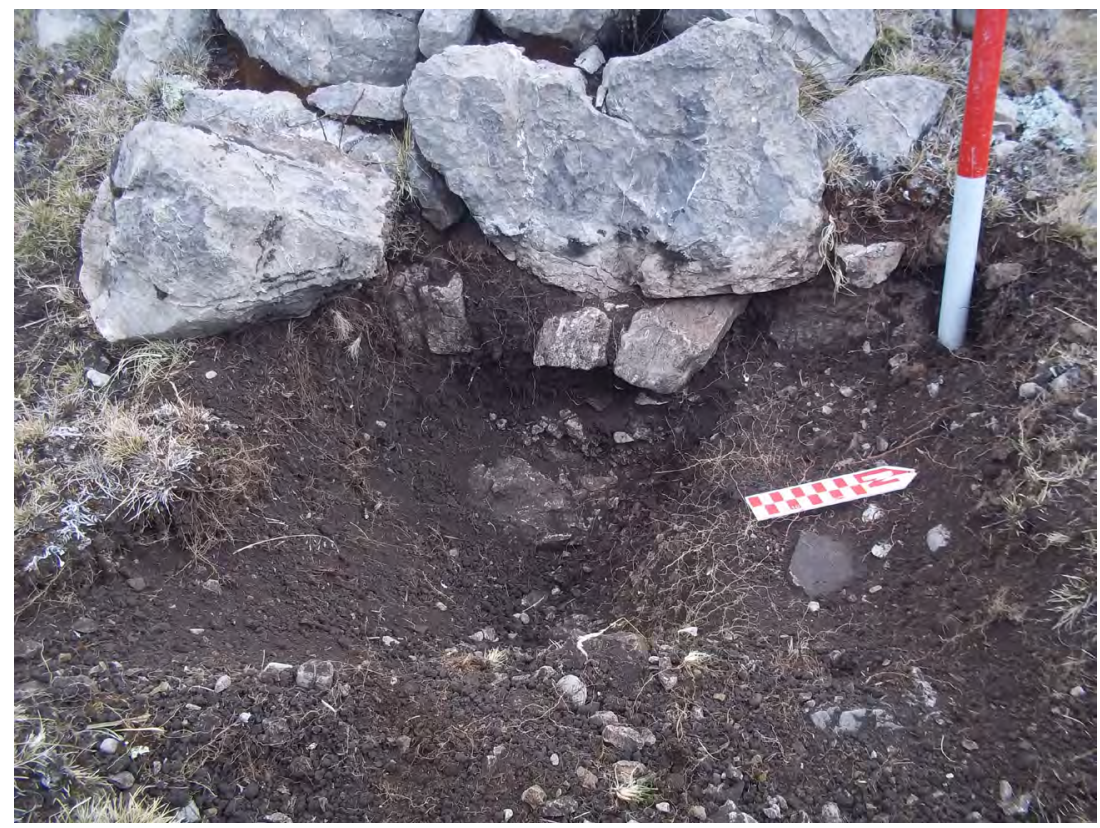

Figura 13. Vista del huaqueo al pie del muro del recinto $N^{\circ} 130$

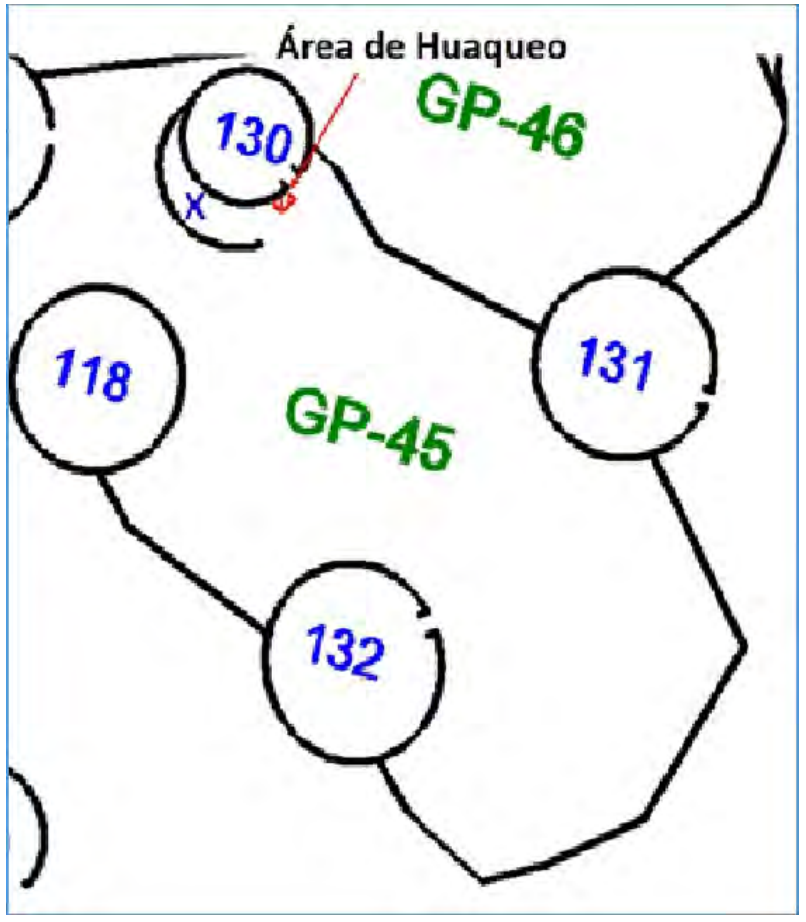

Figura 14.Vista de área de huaqueo, véase el recinto $N^{\circ} 130 y$ “ $X "$. 


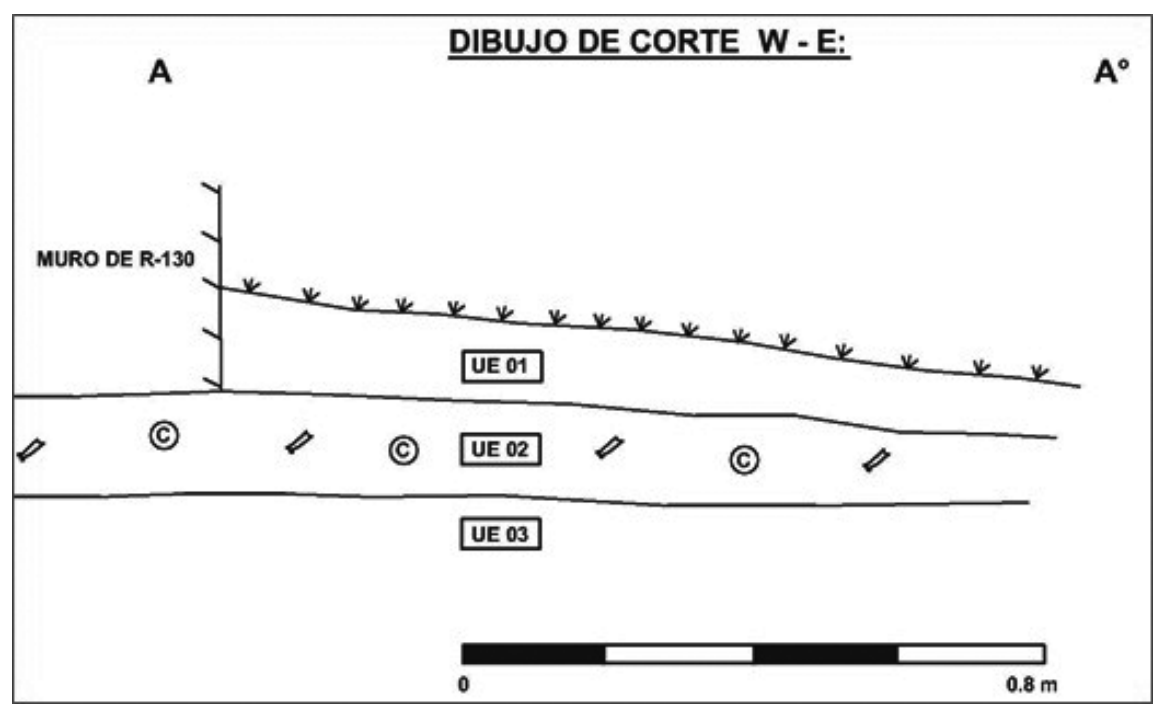

Figura 15. Corte oeste - este, véase las unidades estratigráficas en relación al muro del recinto $N^{\circ} 13$.

UE 03: La UE 03 corresponde a la capa estéril, se encuentra conformado por roca fragmentada, tierra de color negro, piedras angulosas, es de consistencia compacta de textura gruesa, no se registró material cultural asociado, se ubica debajo de la UE 02.

En base a la lectura estratigráfica podemos plantear que previo a la construcción del recinto $\mathrm{N}^{\circ} 130$ en el área se estaban realizando actividades de preparación y consumo de alimentos, esta actividad estaría relacionada con un recinto anterior (recinto $\mathrm{x}$ ) que en un momento posterior fue desmontado y sobre la cual se construyó el recinto 130.

Aprovechando la tierra suelta de la base del huaqueo se extrajo 2 bolsas de muestras de tierra pertenecientes a la UE 02, toda esta fue analizada mediante la aplicación de la metodología de flotación y el uso de zarandas de $2 \mathrm{~mm}, 1 \mathrm{~mm}$ y $0.5 \mathrm{~mm}$, el objetivo fue identificar carporestos (estudio de las semillas, frutos y otros restos que forman parte de ellas). Este análisis estuvo a cargo de la arqueobotánica Lic. Carmela Alarcón Ledesma, en el caso del análisis faunístico, estuvo a cargo de la Mg. Celine Erauw (Ph. Candietion Universite Libre de Bruselas).

Se aplicó la técnica de recuperación en sedimentos conocida como flotación. El tipo de tratamiento de flotación aplicada se denomina "flotación simple manual", esta consiste en vaciar el sedimento en un recipiente con agua, luego se agitó manualmente, lo cual permitió separar los restos de menor densidad subiendo estos a la superficie, posteriormente se vertió el agua con los restos flotando a una columna 
de zarandas de $2 \mathrm{~mm}, 1 \mathrm{~mm}$ y $0.5 \mathrm{~mm}$, los restos más pesados y que no logran flotar fueron también recuperados y denominados muestra pesada (R. Buxo, 1997, p. 33).

El objetivo de esta técnica fue recoger los restos, especialmente semillas y otras partes, que no son vistos a simple vista. Una vez seca las muestras se procedieron a separar los diferentes restos.

Para la identificación de los especímenes se utilizó dos criterios:

- Observación de las características morfológicas, forma, tamaño, textura, etc.

- Comparación con especímenes ya identificados y publicados en catálogos especializados, muestrarios e imágenes.

\section{RESULTADOS}

$1^{\text {ra }}$ Muestra de tierra:

\section{Muestra Ligera}

Cuadro $\mathrm{n}^{\mathrm{0}}$ 1: Vista del cuadro de resultados de muestra ligera

\begin{tabular}{|l|l|l|l|l|}
\hline \multicolumn{1}{|c|}{ TAMIZ } & \multicolumn{1}{|c|}{ IDENTIFICACIÓN } & \multicolumn{1}{c|}{ ÓRGANO } & \multicolumn{1}{c|}{ TAFONÓMIA } & \multicolumn{1}{c|}{ PESO/N $^{\circ}$} \\
\hline $2 \mathrm{~mm}$ & NI (No identificado) & raíz y fibra & fragmentado & $2.4 \mathrm{gr}$ \\
\hline $2 \mathrm{~mm}$ & NI & carbón & fragmentado & \\
\hline $1 \mathrm{~mm}$ & $\begin{array}{l}\text { Chenopodium quinoa } \\
\text { (quinua) }\end{array}$ & semillas & quemado & $0.3 \mathrm{gr} . / 29$ semillas \\
\cline { 2 - 5 } & NI & fibra & fragmentada & $0.5 \mathrm{gr}$ \\
\hline $0.5 \mathrm{~mm}$ & NI & fibra & fragmentada & $0.2 \mathrm{gr}$ \\
\hline
\end{tabular}

\section{Muestra Pesada}

Cuadro $\mathrm{N}^{\circ} 02$. Vista del cuadro de resultados de muestra pesada

\begin{tabular}{|c|l|l|l|c|}
\hline TAMIZ & \multicolumn{1}{|c|}{ IDENTIFICACIÓN } & \multicolumn{1}{|c|}{ ÓRGANO } & \multicolumn{1}{c|}{ TAFONÓMIA } & PESO/N \\
\hline \multirow{3}{*}{$2 \mathrm{~mm}$} & animal NI & óseo & fragmentado & $32.7 \mathrm{gr}$ \\
\cline { 2 - 6 } & mineral NI & NI & fragmentado & $35.8 \mathrm{gr}$ \\
\cline { 2 - 6 } & lítico & NI & lasca & $7.9 \mathrm{gr}$ \\
\cline { 2 - 6 } & NI & fibra & fragmentado & $2.4 \mathrm{gr}$ \\
\hline $1 \mathrm{~mm}$ & animal & óseo & fragmentado & $0.5 \mathrm{gr}$ \\
\hline $0.5 \mathrm{~mm}$ & animal & óseo & fragmentado & $0.1 \mathrm{gr}$ \\
\hline
\end{tabular}


$2^{\text {da }}$ Muestra de tierra:

Muestra Ligera

Cuadro $\mathrm{N}^{\circ} 03$. Vista del cuadro de resultados de muestra ligera

\begin{tabular}{|l|l|l|l|l|l|}
\hline TAMIZ & \multicolumn{1}{|c|}{ IDENTIFICACIÓN } & \multicolumn{1}{|c|}{ ÓRGANO } & \multicolumn{1}{c|}{ TAFONÓMIA } & \multicolumn{1}{|c|}{ PESO/N } & CANTIDAD \\
\hline $2 \mathrm{~mm}$ & NI & Fibra/ raíces & fragmentado & ND & \\
\hline \multirow{2}{*}{$1 \mathrm{~mm}$} & Poaceae 1 & inflorescencia & fragmentado & ND & 4 \\
\hline \multirow{3}{*}{$0.5 \mathrm{~mm}$} & Oxalidaceae - Oxalis sp. & semilla & completa & ND & 5 \\
\cline { 2 - 7 } & Poaceae 2 & semilla & completa & ND & 3 \\
\cline { 2 - 7 } & Asteraceae & semilla & completa & ND & 3 \\
\hline
\end{tabular}

Cuadro $\mathrm{N}^{\circ} 04$. Vista del cuadro de resultados de muestra pesada

\begin{tabular}{|l|l|l|l|l|}
\hline \multicolumn{1}{|c|}{ TAMIZ } & IDENTIFICACIÓN & \multicolumn{1}{c|}{ ÓRGANO } & \multicolumn{1}{c|}{ TAFONÓMIA } & \multicolumn{1}{c|}{ PESO/N } \\
\hline $2 \mathrm{~mm}$ & camélido & óseos & fragmentado & $103,8 \mathrm{gr}$ \\
\hline $1 \mathrm{~mm}$ & S.M & & & \\
\hline $0.5 \mathrm{~mm}$ & S.M & & & \\
\hline
\end{tabular}

En el caso de las muestras de los tamices de $1 \mathrm{~mm}$ y $0.5 \mathrm{~mm}$, la observación morfológica se realizó a través de un Binocular Stereo Coin Microscope-AmScope Supplies 1X-3X, respectivamente.

A través del presente cuadro, podemos establecer la presencia de los siguientes materiales botánicos y óseos:

- Fragmentos de carbón no identificado

- Fragmentos de óseo animal no identificado ( ver figuras 16, 17 y 18)

- Chenopodium quinoa (quinua) carbonizada (ver figuras 19 y 20)

- Fragmentos de óseo animal, camélidos ( ver figuras 21, 22, 23 y 24)

\section{DISCUSIÓN Y CONCLUSIONES}

Como primer punto consideramos necesario mencionar que el sector B y el asentamiento, en general, fueron creciendo progresivamente y es probable que las necesidades y el número creciente de las personas obligara a que se construyeran nuevos "grupos-patio" en áreas colindantes.

El crecimiento de los asentamientos del Periodo Intermedio Tardío es tratado por Lavallée y Julien (1983) para la zona de los Astos, mencionan que los asentamientos Tardíos fueron edificados progresivamente, los pobladores habrían aprovechado en 
Cuadro $\mathrm{N}^{\circ} 05$

Vista del cuadro de resultados del análisis de restos óseos correspondientes a la muestra pesada

\begin{tabular}{|c|c|c|c|c|c|c|c|c|c|c|}
\hline ESPECIE & NR & $\begin{array}{l}\text { ELEMENTO ES- } \\
\text { QUELETICO }\end{array}$ & $\mathrm{D} / \mathrm{I}$ & MEDIDAS & $100 \%$ & $>50 \%$ & $<50 \%$ & $\begin{array}{l}\text { PESO } \\
\text { (GR.) }\end{array}$ & EDAD & MARCAS \\
\hline Camélido & 1 & Ulna-radio & D & & & $\mathrm{X}$ & & 53.08 & $\begin{array}{l}\text { F. } \\
\text { prox }\end{array}$ & Corte \\
\hline Camélido & 1 & Vértebra cervical & & & & & $\mathrm{x}$ & 5.81 & & \\
\hline Camélido & 1 & Carpe intermedio & I & & $\mathrm{X}$ & & & 2.47 & & \\
\hline Camélido & 1 & Tarso 3 & D & & $\mathrm{X}$ & & & 1.68 & & \\
\hline Camélido & 1 & Carpo radial & D & & $\mathrm{X}$ & & & 4.12 & & \\
\hline Camélido & 1 & Carpo ulnar & D & & $\mathrm{x}$ & & & 3.76 & & \\
\hline Camélido & 1 & Maxilar & D & & & & $\mathrm{x}$ & 4.28 & $\mathrm{C} 1+\mathrm{I}$ & \\
\hline Camélido & 8 & $\begin{array}{l}\text { Fragmentos de } \\
\text { huesos largos }\end{array}$ & & & & & & 8.48 & & $\begin{array}{l}\text { Fractura } \\
\text { medular }\end{array}$ \\
\hline Camélido & 20 & $\begin{array}{l}\text { Fragmentos } \\
\text { indeterminados } \\
\text { (varios de crá- } \\
\text { neos) }\end{array}$ & & & & & & 10.05 & & \\
\hline Camélido & 1 & Costilla & & & & & $\mathrm{x}$ & 0.57 & & \\
\hline Camélido & 1 & Costilla & & & & & $\mathrm{x}$ & 0.66 & & \\
\hline Camélido & 1 & Vertebra & & & & & $\mathrm{X}$ & 2.46 & & \\
\hline Camélido & 1 & Vertebra torácica & & & & & $\mathrm{x}$ & 3.62 & & Corte \\
\hline Camélido & 1 & $\begin{array}{l}\text { Fragmento de } \\
\text { hueso largo }\end{array}$ & & & & & & 2.79 & & \\
\hline TOTAL & 40 & & & & & & & 103.83 & & \\
\hline
\end{tabular}




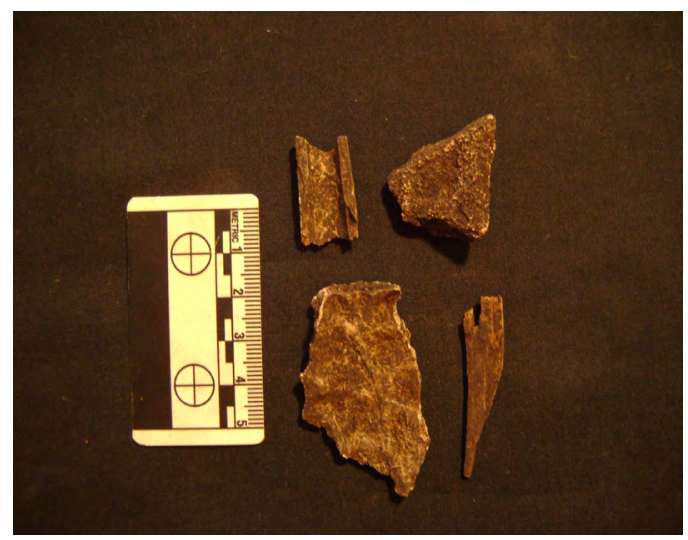

Figuras 16 . Vista de fragmentos de restos óseos de animal resultado de la aplicación en seco de tamiz $2 \mathrm{~mm}$.
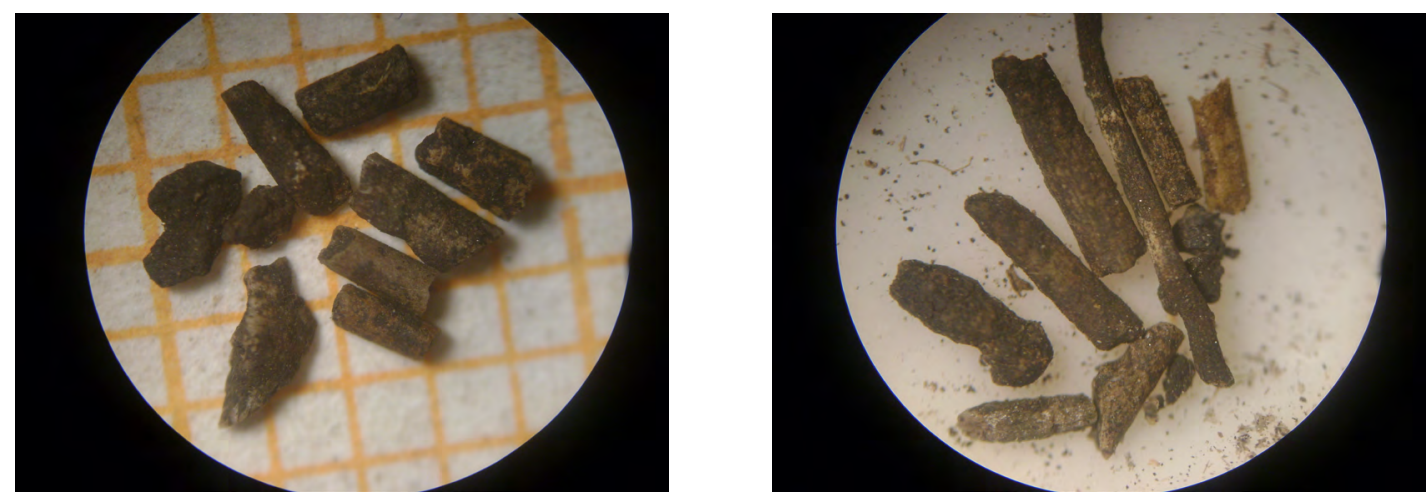

Figura 17 y 18. Vista de fragmentos de restos óseos de animal resultado de la aplicación en seco de tamiz de 0.5 y $1 \mathrm{~mm}$.
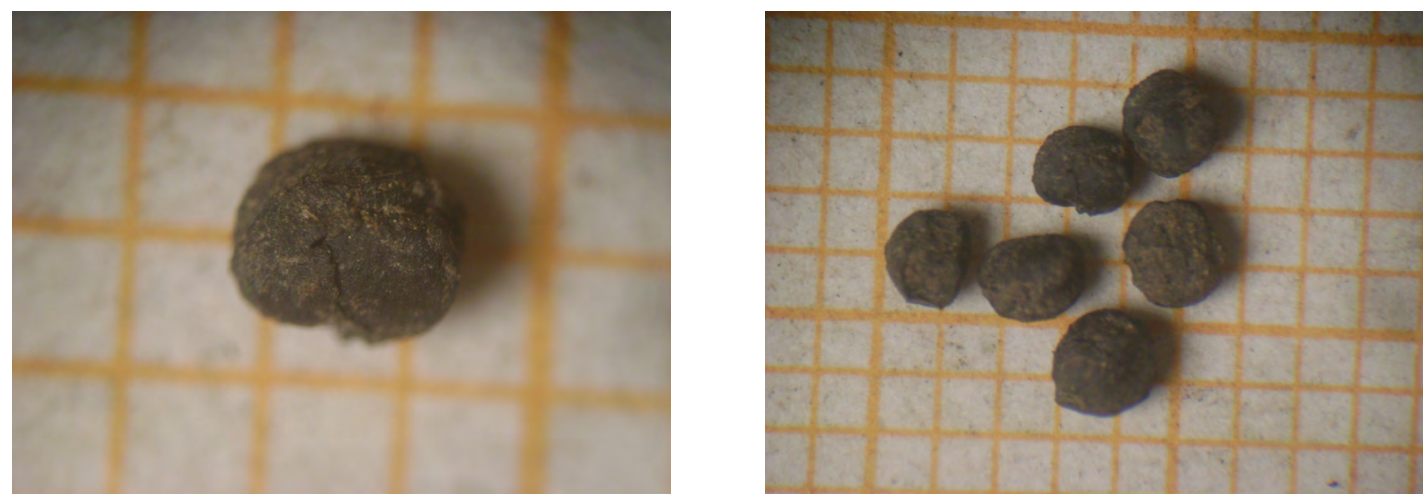

Figura 19 y 20. Vista de Chenopodium quinoa (quinua) carbonizada resultado de la aplicación en seco de tamiz de $1 \mathrm{~mm}$. 

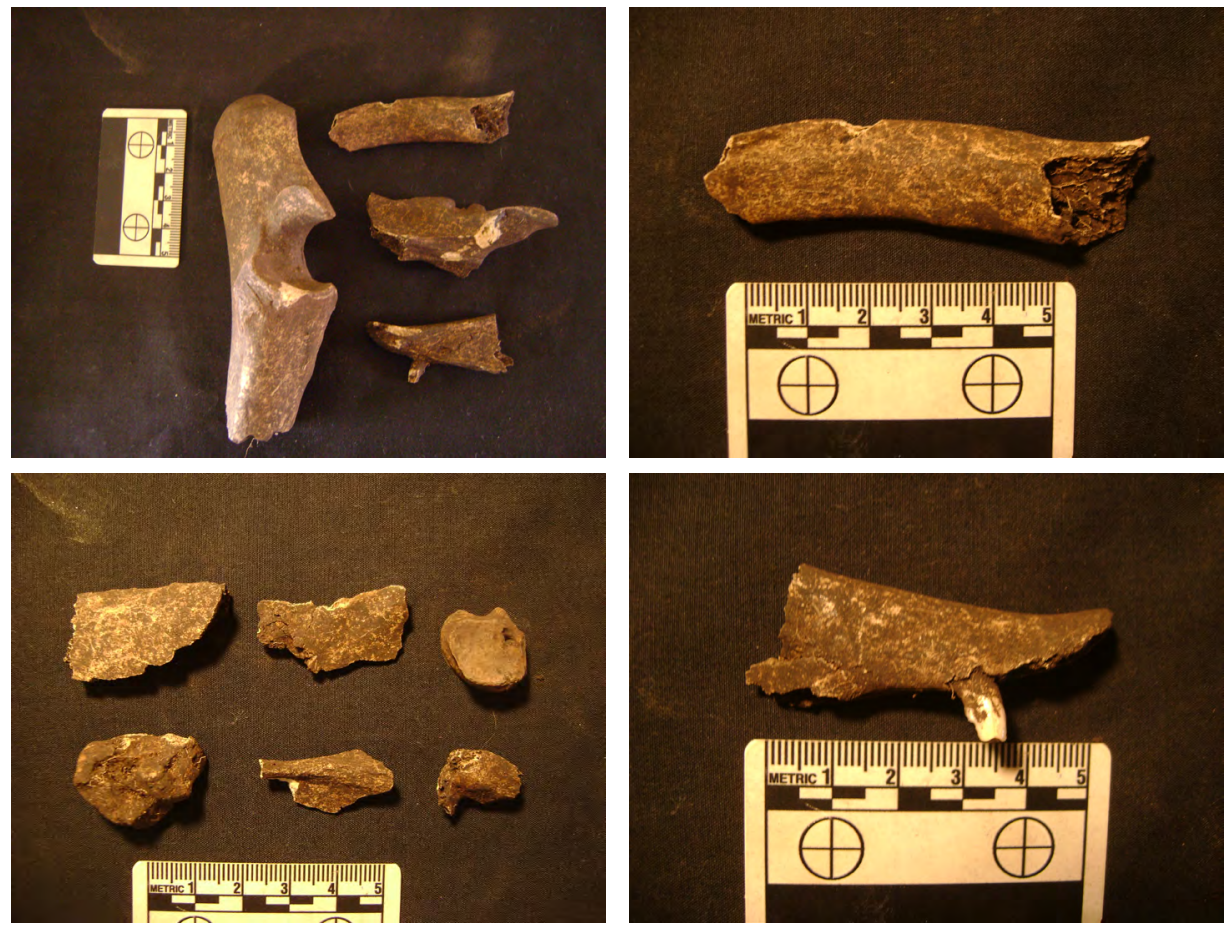

Figuras 21, 22, 23 y 24. Vista de fragmentos de restos óseos correspondientes a camélidos extraídos de la segunda muestra.

un primer momento las superficies planas fáciles de acondicionar, posteriormente fueron construyendo recintos en áreas con pendiente donde fue necesario acondicionarlas mediante la construcción de terrazas. Esto es corroborado también por la presencia densa de unidades alveolares en la parte central de los sitios Astos a comparación con las áreas periféricas en pendiente donde los recintos se limitan a 204 .

Analizando los detalles constructivos de los paramentos de todos los recintos del sector B mencionamos que no hemos hallado alguna diferencia que podría significar temporalidad o presencia de ciertos grupos al interior del sector; sin embargo, esto no significa que el sitio haya sido construido en un solo momento. Llaqtaqasa fue creciendo paulatinamente, al igual que los sitios tardíos de la sierra, esto se puede evidenciar a través de la lectura de la unión de los muros de los componentes arquitectónicos (recintos y patios), la topografía del sector y además podemos utilizar la analogía con otros sitios para comparar el crecimiento del sector (Lavallée y Julien, 1983).

$\mathrm{Al}$ igual que los sitios Astos, la mayor concentración de recintos se dio en la parte plana y central de Llaqtaqasa, probablemente los grupos-patio ubicados al oeste (inmediatamente después de los muros perimetrales) sean los más antiguos, posteriormente se han ido construyendo nuevos grupos-patio hacia el este del sector y por 
último, los construidos sobre terrazas podrían corresponder a un último momento, podemos señalar que el patrón de crecimiento fue horizontal.

Lo que sí queda claro, a través de la observación de los recintos $\mathrm{N}^{\circ} 130, \mathrm{X}, 131$, 132 y 118 correspondiente al GP-45, es que los "grupo-patio" fue la organización básica desde el primer momento de ocupación, posteriormente fueron adosándose nuevos recintos al interior de los grupos-patio o fueron desmontándose recintos y sobre ellos construyéndose otros más grandes o pequeños con otra orientación de acuerdo a las necesidades de las personas.

Entonces, en base a la mención anterior, podemos señalar que los datos obtenidos al pie del recinto $\mathrm{N}^{\circ} 130$ corresponderían a actividades domésticas realizadas en el recinto " $\mathrm{X}$ " en los primeros momentos de ocupación del sector correspondientes al Periodo Intermedio Tardío (1100-1400 d. C.).

Partiendo de estos datos y del análisis de las muestras de tierra del recinto "X" donde se registraron materiales botánicos como la quinua (Chenopodium quinoa) carbonizados, restos de óseo animal correspondientes a camélidos con huellas de corte y restos de carbón, podemos plantear que la actividad económica de los pobladores de Llaqtaqasa correspondía a la ganadería de camélidos y agricultura de altura. Esto también sería corroborado por la presencia de corrales tanto en el sector C como en los alrededores del sitio. La agricultura estaría evidenciada por la presencia de un sistema de andenería ubicado a $500 \mathrm{~m}$ del sitio, a una altitud de $3960 \mathrm{~m} \mathrm{~s}$. n. m., asociada a una pequeña quebrada y ojos de agua y presencia de artefactos líticos como rompeterrones.

La crianza de camélidos podría haberse desarrollado con normalidad en Llaqtaqasa ya que el área cuenta con abundantes zonas de pampas, abrigos rocosos y ojos de agua ubicados en un perímetro de $1.5 \mathrm{~km}$, además en el sector $\mathrm{C}$ hemos registrado una serie de corrales asociados a recintos circulares, este sector cuenta con un gran ojo de agua y a comparación del sector $\mathrm{B}$, se ubica al pie de un afloramiento rocoso y a una menor altura (200 metros inferior) haciendo que la sensación de frío sea menor. Este patrón de ubicación de corrales también es registrado por Lavallée y Julien (1983) para los sitios Astos, mencionan que casi siempre los corrales "estaban protegidos del viento y situadas en dirección al punto de agua más cercano" (Lavallée y Julien, 1983, p. 58). Las construcciones circulares asociadas a los corrales podrían estar destinadas a las personas que cuidaban de ellos o para los animales recién nacidos, por la cantidad de cerámica de función doméstica hallada en superficie en el sector podríamos señalar que estas estructuras servían como viviendas para los pastores.

Hay que señalar también que el sector C y el sector B tienen un desnivel de $200 \mathrm{~m}$ y se encuentran separados por un afloramiento rocoso a modo de precipicio lo que hace complicado el acceso al sector B desde el sector C. 
Por otra parte, la agricultura en Llaqtaqasa se habría desarrollado al norte y en la parte baja de la misma, específicamente en el sistema de andenerías ubicado a 500 $\mathrm{m}$ del asentamiento. Si bien sólo hemos registrado granos de quinua (Chenopodium quinoa) carbonizadas, en esta área se habría realizado, probablemente, el cultivo de otros productos tales como la papa (Solanum tuberosum), oca (Oxalis tuberosa), mashua (Tropaeolum tuberosum) entre otros.

Descartamos el cultivo del maíz (Zea mays) por ser un producto que requiere de condiciones adecuadas para su crecimiento tales como agua permanente, temperatura adecuada, entre otras; además, en la actualidad, se cultiva por debajo de los $3200 \mathrm{~m}$ s.n.m. Sin embargo, no descartamos que este producto haya sido consumido por los pobladores de Llaqtaqasa tal y como se registró en los sitios Astos de Shanki y Chuntamarka por Lavallée y Julien (1983); si asumimos ese supuesto podríamos señalar que habría otros modos de conseguir este producto ya sea a través de trueques o un control sobre ciertos territorios en el valle del Pampas.

En vista de este último, planteamos como hipótesis que los pobladores de Llaqtaqasa tuvieron contacto con el valle del río Pampas, esto se ve evidenciado por la presencia de cantos rodados en el sector A y B usados como manos de mortero, estos debieron de ser extraídos de la ribera del río Pampas, ya que es el más cercano al asentamiento. Por otra parte, resultaría extraño que siendo el valle en la actualidad un lugar donde se viene cultivando una variedad de productos propios de la zona no haya sido aprovechado durante el Intermedio Tardío. Más aún cuando se tienen datos de la presencia de un posible camino inca que uniría esta parte del valle con Vilcas Huamán durante el Periodo Horizonte Tardío.

Durante la Colonia, en esta parte del valle se han instalado una serie de haciendas, obrajes y reducciones como la hacienda de Astania, hacienda de Pacomarca, hacienda Mejorada, hacienda Occenay, hacienda Santa Rita, reducción de Concepción; hacia el norte (pasado el pueblo de Concepción) tenemos el obraje de Ccaccamar$\mathrm{ca}$, la hacienda de Ninabamba, entre otros, esta zona fue aprovechada al máximo y creemos que esto viene desde periodos tardíos.

Entonces, la presencia de granos de quinua en gran cantidad al interior de la muestra analizada y los restos óseos de camélidos con huellas de corte registrados nos permite plantear que los pobladores de Llaqtaqasa tuvieron una economía complementaria basada en la agricultura de altura y la crianza de camélidos, además, probablemente, hayan tenido acceso a productos del valle, futuros trabajos corroborarán lo planteado. 
AGRADECIMIENTOS: Mi profundo agradecimiento a la Lic. Carmela Alarcón Ledesma, quién se encargó del análisis de las muestras de tierra. Asimismo mi gratitud hacia mis padres Luis Martínez Fuentes y Cristina Sulca Lara, quiénes me apoyaron en cada etapa de investigación, al profesor PhD. Jorge Silva por su contante orientación académica en los diferentes procesos de investigación.

Por último, mis agradecimientos a mi compañero y colega José Bazán, a Jacquely Karim Tarazona, quién se encargó de la elaboración de los planos, asimismo a Roxana Mendoza por el apoyo en los trabajos de campo, a mi primo el Ing. Fredy Sulca, quién realizó los trabajos de levantamiento planimétrico y topográfico del sitio.

Mi eterna gratitud a todos ellos.

\section{REFERENCIAS BIBLIOGRÁFICAS}

Archivo General de la Nación (AGN). "Títulos de la chacra de Astania en Vischongo-Vilcashuamán". (1715). Fondo "índice campesinado (título de propiedad), legajo 24, cuaderno 449, Folio 22.

Castro Jáuregui, Jhonatan. (2007). Prospección Arqueológica en la cuenca del río Itanayuq (Pujas- Vilcas Huamán. (Informe de prácticas pre profesional) Universidad Nacional San Cristóbal de Huamanga, Ayacucho.

Carabajal, Pedro. (1965). Descripción fecha de la provincia de Vilcashuamán por el ilustre señor don Pedro de Carvajal, corregidor y justicia mayor della. En Jiménez de la Espada (Eds), Relaciones geográficas de Indias (pp. 205-219).

Cahud, Carlos. (1966). Investigación Arqueológica en Vilcas Huamán. (Informe de investigación). Universidad Nacional San Cristóbal de Huamanga, Ayacucho.

Cisneros, Rubén. (2011). Reconocimiento arqueológico en la margen izquierda del río Pampas, Huambalpa, provincia de Vilcas Huamán- Ayacucho. (Informe de prácticas Pre profesionales). Universidad Nacional San Cristóbal de Huamanga, Ayacucho.

Cook, D. (Ed.). (1975). Tasa de la Visita General de Francisco de Toledo. Lima: Universidad Nacional Mayor de San Marcos.

Earle, Timothy. (1987). Chiefdoms in archaeological and ethnohistorical perspective. Annual Review of Anthropology, 16, pp. 279-308.

Garcilaso, V. (1976 [1609]). Comentarios Reales de los Incas (tomo I). Editado por Aurelio Miró Quesada, Caracas: Biblioteca Ayacucho.

Gonzales Carré, Pozzi-Escot D. y Vivanco Cirilo (1987). Los chankas: Cultura material. Laboratorio de Arqueología de la Universidad Nacional San Cristóbal de Huamanga. Ayacucho 
Guamán POMA, Felipe. (1980 [1615]). Nueva Corónica y Buen Gobierno. En Franklin Pease (Ed.) (1 $1^{\text {ra }}$ ed.). Venezuela: Biblioteca Ayacucho Caracas.

Guzmán, Carlos. (1959) Investigaciones Arqueológicas en Vilcas Huamán, departamento de Ayacucho (tesis presentada para optar el grado de bachiller en Humanidades). Universidad Nacional Mayor de San Marcos, Lima.

Lavalée Daniélle y JULIEN Michéle. (1983). Asto: Curacazgo prehispánico de los Andes Centrales ( $1^{\text {ra }}$ ed.). Lima. Instituto de Estudios Andinos.

Lumbreras, Luis Guillermo. (1959) Sobre los Chankas. Actas y Trabajos del II Congreso Nacional de Historia del Perú, 1, pp. 211-242.

Mendoza, Ronald. (2014). Prospección Arqueológica en el Sureste del Distrito de Vilcas Huamán, Ayacucho (informe de prácticas pre profesional). Universidad Nacional San Cristóbal de Huamanga, Ayacucho.

Mendoza, Edison. (2007). Reconocimiento Arqueológico en la margen izquierda de los ríos Yana Mayu y Pampas, Vilcas Huamán (informe de prácticas pre profesionales). Universidad Nacional San Cristóbal de Huamanga, Ayacucho.

Mendoza, Edison. (2010). Investigaciones Arqueológicas en la margen izquierda de los ríos Yanamayu y Pampas, Vilcas Huamán- Ayacucho. PACHA RUNA 1, UNSCH. 1, pp. 123-162.

Mendoza, Edison. (2010). Contextos rituales Tardíos, en el centro ceremonial Formativo de Campañayuq Rumi, Vilcas Huamán-Ayacucho (tesis para optar el título de licenciado en Arqueología) Universidad Nacional San Cristóbal de Huamanga, Ayacucho.

Mendoza, Edison. (2019). Arqueología de Vilcashuamán-Ayacucho (1 ${ }^{\text {ra }}$. ed.). España: Editorial Académica Española.

Ochante Hermoza, Celestino. (2001). Prospección Arqueológica en el distrito de Concepción-Vilcas Huamán (Informe de prácticas Pre Profesionales). Universidad Nacional San Cristóbal de Huamanga, Ayacucho.

Pulgar, Javier. (1996). Las ocho regiones naturales, la regionalización transversal ( $7^{\mathrm{ma}} \mathrm{ed}$.). Lima. PEISA.

Quijano, Alex. (2010). Prospección Arqueológica entre las quebradas de Saurama y Urpay Puquio, Carhuanca- Ayacucho (informe de prácticas pre-profesionales). Universidad Nacional San Cristóbal de Huamanga, Ayacucho.

Quispe Valerio y Rojas Wilmer. (2010). Reconocimiento Arqueológico en la margen izquierda del Río Qatunmayo, Vischongo-Ayacucho (informe de prácticas pre-profesionales). Universidad Nacional San Cristóbal de Huamanga, Ayacucho. 
Vaquerizo, Fernando. (2003). Prospección Arqueológica en San Antonio de Cocha, Distrito de Huambalpa, Provincia de Vilcas Huamán- Ayacucho (informe de prácticas pre profesionales). Universidad Nacional San Cristóbal de Huamanga, Ayacucho.

\section{SOBRE LA AUTORA}

\section{Winnie Celeste Martínez Sulca}

Bachiller en Ciencias Sociales con especialidad en Arqueología por la Universidad Nacional Mayor de San Marcos (UNMSM), próxima a sustentar la tesis de licenciatura "Llaqtaqasa, un sitio habitacional del Periodo Intermedio Tardío (1100-1400 d. C) distrito de Concepción, provincia Vilcas Huamán-Ayacucho" (plan de tesis aprobada bajo resolución de decanato $\mathrm{N}^{\circ}$ 0640-D-FCCSS-2018). Interesada en el estudio de sitios del Periodo Intermedio Tardío en la región Ayacucho y en el tema de caminos incaicos. Ha participado en varios proyectos de investigación siendo la última, el proyecto Qhapaq Ñan, tramo Vilcashuamán-Sangalla del Ministerio de Cultura, sede central. 